This work is licensed under a Creative Commons Attribution 3.0 License.

Research article

urn:1sid:zoobank.org:pub:69DE247F-A00E-48B1-845F-191C0FC03F8B

\title{
Ballomma, a new Afrotropical genus in the Cryptothelinae (Araneae, Zodariidae): eyes on the run
}

\author{
Rudy JOCQUÉ ${ }^{1, *}$ \& Arnaud HENRARD ${ }^{1,2}$ \\ ${ }^{1}$ Royal Museum for Central Africa, B-3080 Tervuren, Belgium. \\ ${ }^{2}$ Earth and Life Institute, Biodiversity research Center, UCL-17.07.04. Bâtiment Carnoy, \\ Croix du Sud, 5, B-1348, Louvain-la-Neuve, Belgium. \\ *Corresponding author: rudy.jocque@africamuseum.be \\ ${ }^{2}$ Email: arnaud.henrard@gmail.com \\ ${ }^{1}$ urn:Isid:zoobank.org:author:CF15016C-8CD1-4C9D-9021-44CA7DC7A5D5 \\ 2 urn:1sid:zoobank.org:author:E1B02E6E-D91C-43FE-8D8C-CD102EFEE3B4
}

\begin{abstract}
Ballomma gen. nov. is described in the zodariid subfamily Cryptothelinae. It is characterized by the pairs of adjacent anterior median eyes and anterior lateral eyes and triangular palpal tarsus in the female, the concave tegulum with thin embolus in the male. Apart from the type species B. erasmus gen. et sp. nov. ( $\hat{\jmath}+$ ), the genus contains $B$. haddadi gen. et sp. nov. ( $\left.\jmath^{\lambda}+\right), B$. neethlingi gen. et sp. nov. $\left(\delta^{A}+\right.$ ), and B. legala gen. et sp. nov. (ㅇ). A key to the species is provided. The restricted distribution of the genus is discussed.
\end{abstract}

Keywords. South Africa, Limpopo Province, montane forest, Aschema.

Jocqué R. \& Henrard A. 2015. Ballomma, a new Afrotropical genus in the Cryptothelinae (Araneae, Zodariidae): eyes on the run. European Journal of Taxonomy 163: 1-24. http://dx.doi.org/10.5852/ejt.2015.163

\section{Introduction}

The Cryptothelinae remain a subfamily within the Zodariidae in which numerous novelties are to be expected. The recent description of Palindroma Jocqué \& Henrard, 2015 with the discovery of a novel synapomorphy for the family, is symptomatic for this lack of knowledge. The subfamily has its distribution centre in southern Africa. Although South Africa has been fairly well inventoried in the last few years by the SANSA initiative (Dippenaar-Schoeman et al. 2015), many new taxa remain to be discovered such as in Limpopo, the northernmost province of the country. The area is characterized by a complex mosaic of biomes, with a high degree of endemism. Some of the mountain areas are among the oldest on the African continent and harbour species that belong to old evolutionary lineages (Jocqué et al. 2013). The species Australutica africana Jocqué, 2008 is one of these (Jocqué 2008). It was found in a thoroughly inventoried area in the Soutpansberg (Foord et al. 2008). Many of the other less important mountain ranges have only been inventoried superficially, but the few collections that have been made there, reveal a highly diverse fauna, often containing species with surprising affinities. 
Here we describe a new genus with four new species, all collected at medium altitude in the Limpopo Province. One of the most remarkable characters of the genus is the position of the ALE which are very close together, an eye arrangement which is particularly rare. These eyes would not be recognized as ALE without the observation of intermediate positions between lateral and central in related genera.

\section{Material and methods}

Specimens were observed, drawn and measured with a WILD M 10 stereo microscope. Details of the female genitalia and male palps were observed with a Zeiss Stemi 2000 stereo microscope. Measurements and photographs of the habitus, details of mouthparts, detached male palps and female genitalia were taken with a Leica MZ16 using the LAS automontage software (ver. 3.8). The female genitalia were dissected and digested with pancreatin then immersed in $75 \%$ ethanol.

For scanning electron micrographs (SEM) photos, specimens were dried in Hexamethyldisilazane (36h), gold coated and examined and photographed with a JEOL 6480 LV scanning electron microscope. Types are deposited in the National Collection of Arachnids, Pretoria (NCA) and the Royal Museum for Central Africa, Tervuren, Belgium (MRAC).

All measurements are in mm. All palp illustrations are from left palps.

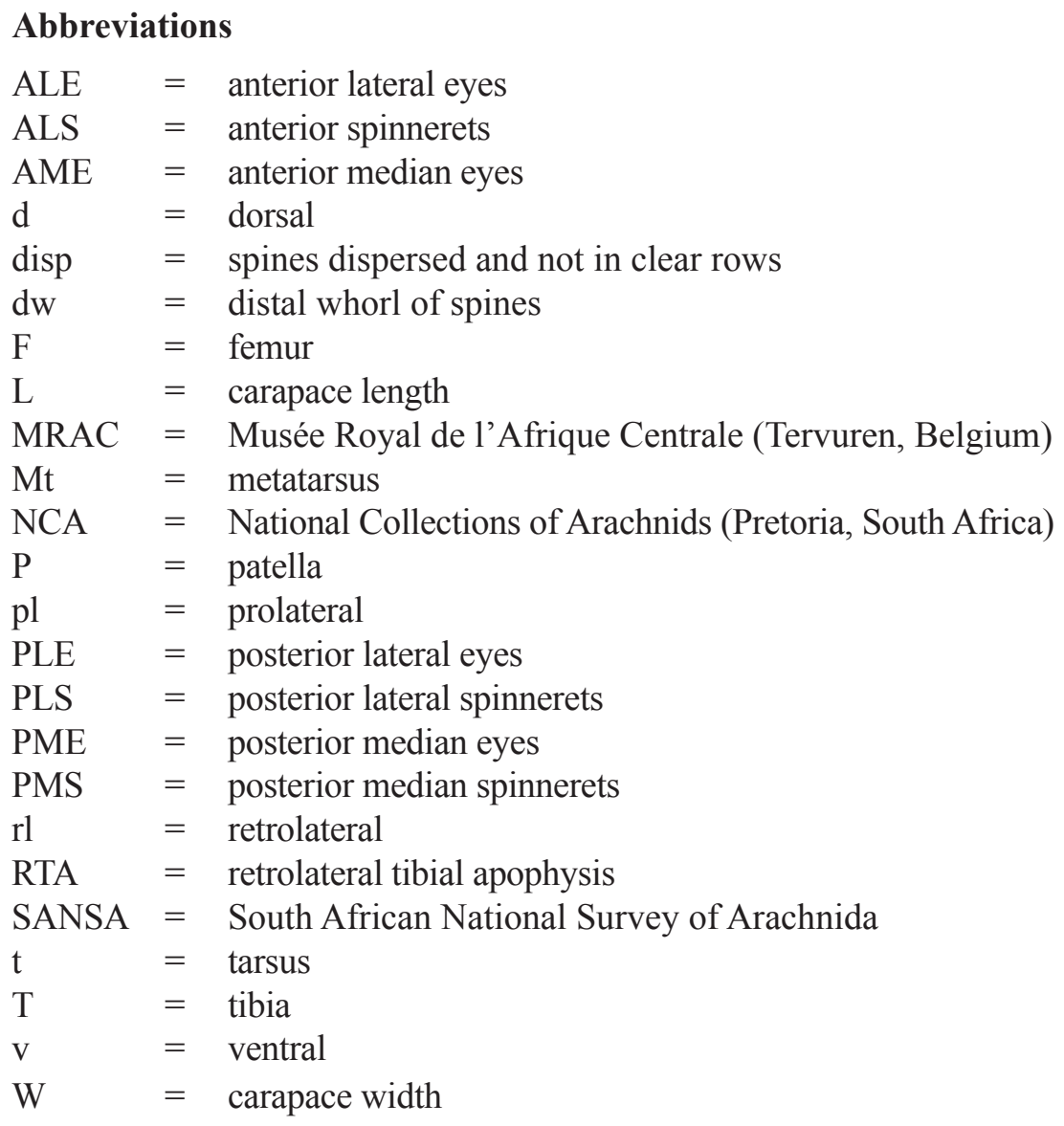


JOCQUÉ R. \& HENRARD A., Ballomma, a new genus in the Zodariidae

\title{
Taxonomy
}

\author{
Class Arachnida Cuvier, 1812 \\ Order Araneae Clerck, 1757 \\ Family Zodariidae Thorell, 1881 \\ Subfamily Cryptothelinae Simon, 1892 \\ Ballomma gen. nov. \\ urn:lsid:zoobank.org:act:CF0FE505-E714-4A09-8575-CFFC06C32C9A
}

\section{Type species}

Ballomma erasmus gen. et sp. nov.

\section{Diagnosis}

Ballomma gen. nov. is a member of the Cryptothelinae characterized by the eye position with touching ALE and AME, the shield-shaped sternum without or with tiny precoxal sclerites, the female palp with triangular flattened palpal tarsus, the male palp with concave tegulum accommodating the thin, slightly curved embolus directed diagonally over the tegulum and the epigyne with cul-de-sac ducts.

\section{Etymology}

The genus name is derived from the combined Greek terms $\beta \alpha \lambda \lambda \omega$ (= to touch) and o $\mu \mu \alpha$ (=eye), referring to the touching anterior lateral eyes. The gender is neuter.

\begin{abstract}
Affinities
Ballomma gen. nov. clearly belongs to the Cryptothelinae, a subfamily of the Zodariidae that has been characterized by nomenclatorial problems: poor definitions and misplacements (Jocqué 1991; Jocqué \& Henrard 2015). It has the modified endites and an eye position of a type that only occurs in that subfamily. The present genus has some superficial resemblance with Capheris Simon, 1887 with which it shares the triangular female palpal tarsus and the closely set AME and ALE. However, in Ballomma gen. nov. the eyes are even more closely set and characters of sternum, carapace profile and structure of the genitalia are all different. As for the latter character there is a superficial resemblance with Aschema Jocqué, 1991 from Madagascar in which the ALE and AME are also very closely set. The shape of a number of undescribed Aschema species have somatic and genitalic characters that come close to those of the Ballomma gen. nov. species in the present article. However, the characteristics of the sternum and carapace and of the genitalia, and the modified leg IV, clearly separate them from the genus here described.
\end{abstract}

\section{Description}

HaBitus. Medium size to small spiders (4.5-7.5) with smooth teguments. Carapace longer than wide ( $\mathrm{L} / \mathrm{W}<1.4-1.6)$, without setae apart from a few longer hairs on clypeus; widest at level of coxae II-III, narrowed to about $0.43-0.66$ times maximum width in eye region (cephalic width measured on posterior tangent of PME). Cervical grooves poorly indicated. Profile: flat; fovea in shallow depression.

Colouration. Carapace medium brown; chelicerae, legs, mouthparts and sternum medium to orange brown; abdomen dorsum with complex dark pattern on pale background; in some cases with four apodemes, sides grey, venter pale sometimes with dark pattern; in males sclerotized in front of epigastric fold and slightly sclerotized in front of spinnerets.

EYEs. In three rows; ALE in front of AME and touching each other; AME close together sometimes touching; posterior row recurved, eyes apart. All eyes pale and subequal. Clypeus retreating, height 2.5 to 3.6 times diameter of AME, with some dispersed setae. 
Prosoma. Chilum double, sometimes poorly delimited, slightly more than twice as wide as high; no setae. Chelicerae conical with many evenly dispersed setae; fangs shorter than wide at base. Labium triangular, narrowed base. Endites roughly triangular, converging, with basolateral extension accommodating palpal coxae. Sternum shield-shaped, as wide as long or slightly longer than wide, without triangular extensions or precoxal sclerites; anterior margin straight, lateral margins slightly sinuous.

Legs. Slender; formula 4123. Spination reduced on legs I and II, well developed on III and IV with spines numerous on T and Mt III and IV. Spines slender. With few or without hinged hairs.

Female PALP. With tarsus triangular and flattened, with row of prolateral thorns, retrolaterally with some thin spines; palpal claw with some small teeth at base; turned inward over less than $35^{\circ}$; without distal patch of chemosensitive setae.

ABdomen. Oval; tracheal spiracle small, somewhat advanced. Females and juveniles with six spinnerets. Female ALS large, conical, biarticulate. PLS without, PMS with one cylindrical gland spigot. Colulus represented by field with few setae.

Male PalP. Patella sometimes with swelling; RTA variable; cymbium with well developed basal flange and with group of truncated subapical thorns; subtegulum strongly developed, with transverse ridges; tegulum with prolateral concavity, distally with dorsal and ventral extensions; accommodating thin, slightly curved embolus, directed diagonally over tegulum. Epigyne simple, with internal structure characterized by cul-de-sac ducts, visible in transparency.

\section{Distribution}

Ballomma gen. nov. is so far only found in the mountain forests of the Limpopo Province in northern South Africa.

Key to the species (male of $B$. legala unknown)

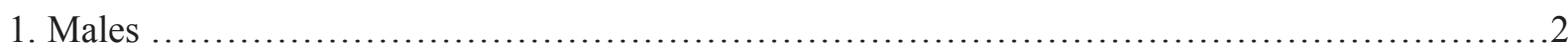

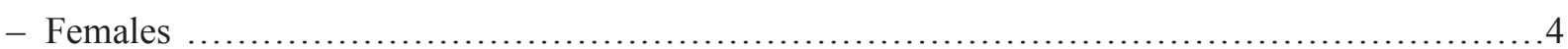

2. Area in front of epigastric fold with field of spinules (Figs 1D, 11C); embolus base without or with small

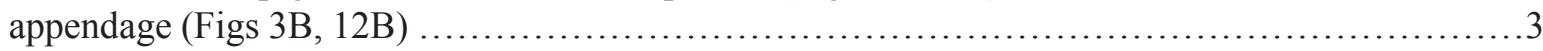

- Area in front of epigastric fold without field of spinules; embolus base with large, strongly sclerotized pointed appendage (Fig. 7B)

B. haddadi gen. et sp. nov.

3. Distal part of RTA with transparent concave part (Fig. 12A); embolus almost straight, short, half as long as tegulum, tegular process small, directed medially (Fig. 12B) ........... B. neethlingi gen. et sp. nov.

- Distal part of RTA without transparent concave part (Fig. 3A); embolus curved, almost as long as tegulum, tegular process larger, directed apically (Fig. 3B) ........... B. erasmus gen. et sp. nov.

4. Frontal part of epigyne with V-shaped ducts visible in transparency (Figs 10A, B), anterior part of endites with field of strong spinules (Fig. 9E) .......................... legala gen. et sp. nov.

- Frontal part of epigyne without V-shaped pattern (Figs 3C, 7C); endites without spinules ...........5

5. Pattern of internal structure of epigyne $\mathrm{X}$-shaped (Fig. 12C) .....B. neethlingi gen. et sp. nov.

- Pattern of internal structure of epigyne not X-shaped (Figs 3C, 7C) ........................6

6. Pattern of epigyne with two ring-shaped ducts in front, followed by procurved cul-de-sac ducts (Fig. 3C) ....................................................... erasmus gen. et sp. nov.

- Pattern of epigyne with cul-de-sac ducts in front, without ring-shaped ducts (Fig. 7C) 
JOCQUÉ R. \& HENRARD A., Ballomma, a new genus in the Zodariidae

Ballomma erasmus gen. et sp. nov.

urn:1sid:zoobank.org:act:A6681529-ED54-46CF-B39D-E7862EBED809

Figs 1A-D, 2A-D, 3A-C, 4A-D, 5A-C, 14

\section{Diagnosis}

The male of B. erasmus gen. et sp. nov. is easily recognized by the field of spines in front of the epigastric fold and the RTA with three short elements. The female is characterized by the S-shaped ducts in the anterior half of the epigyne.

\section{Etymology}

The species name is a noun in apposition taken from the type locality.
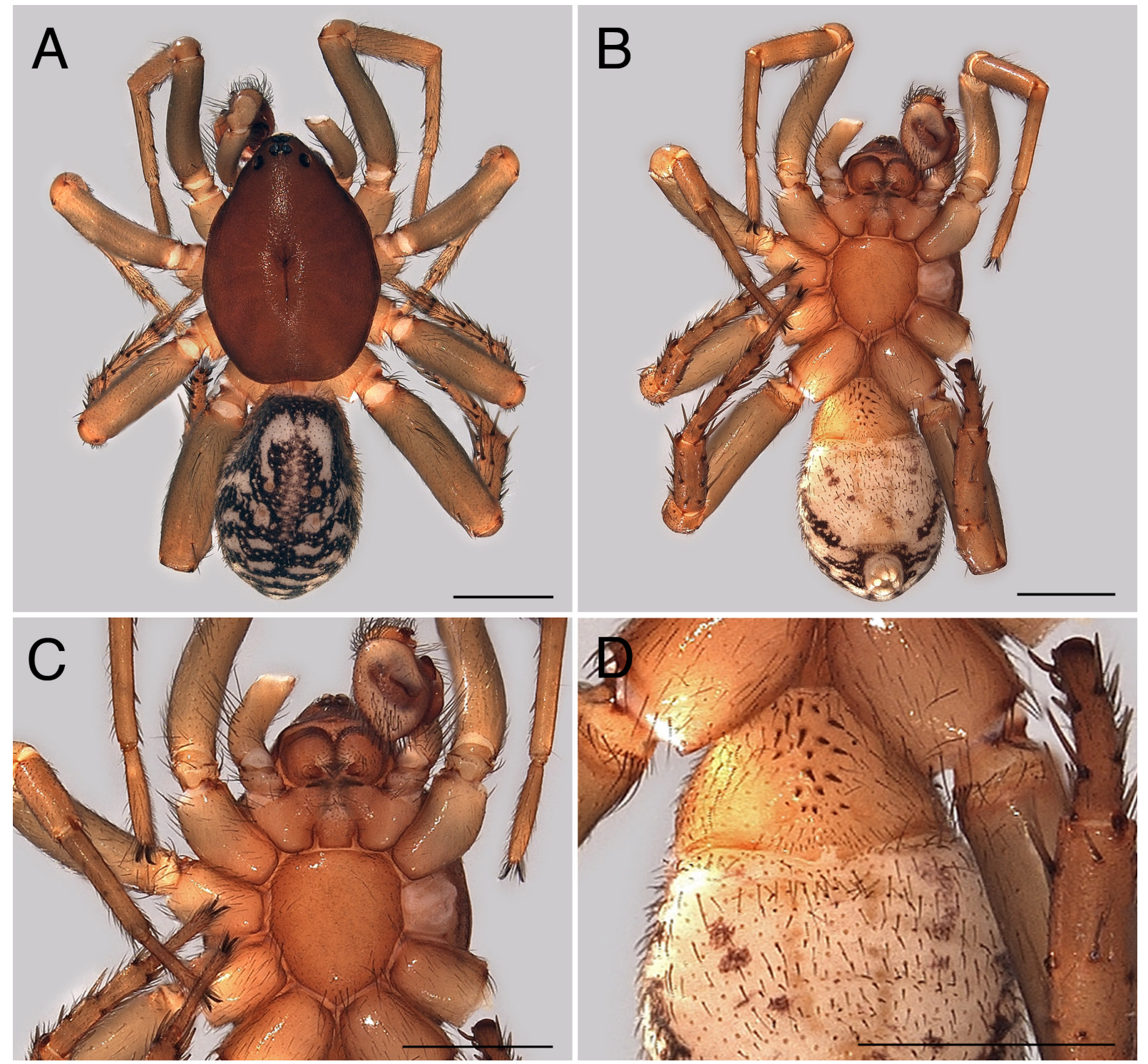

Fig. 1. Ballomma erasmus gen. et sp. nov. Holotype, §. A. Habitus, dorsal view. B. As preceding, ventral view. C. Prosoma, ventral view. D. Abdomen, ventral view. Scale bars: $1 \mathrm{~mm}$. 


\section{Type material}

\section{Holotype}

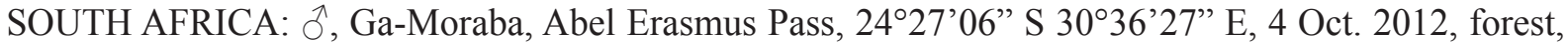
sifting litter, J.A. Neethling (NCA 2015/3485; ex MRAC 241636).

\section{Paratypes}

SOUTH AFRICA: $3 q q$, same data as holotype ( $1 q$ kept in MRAC 241636).
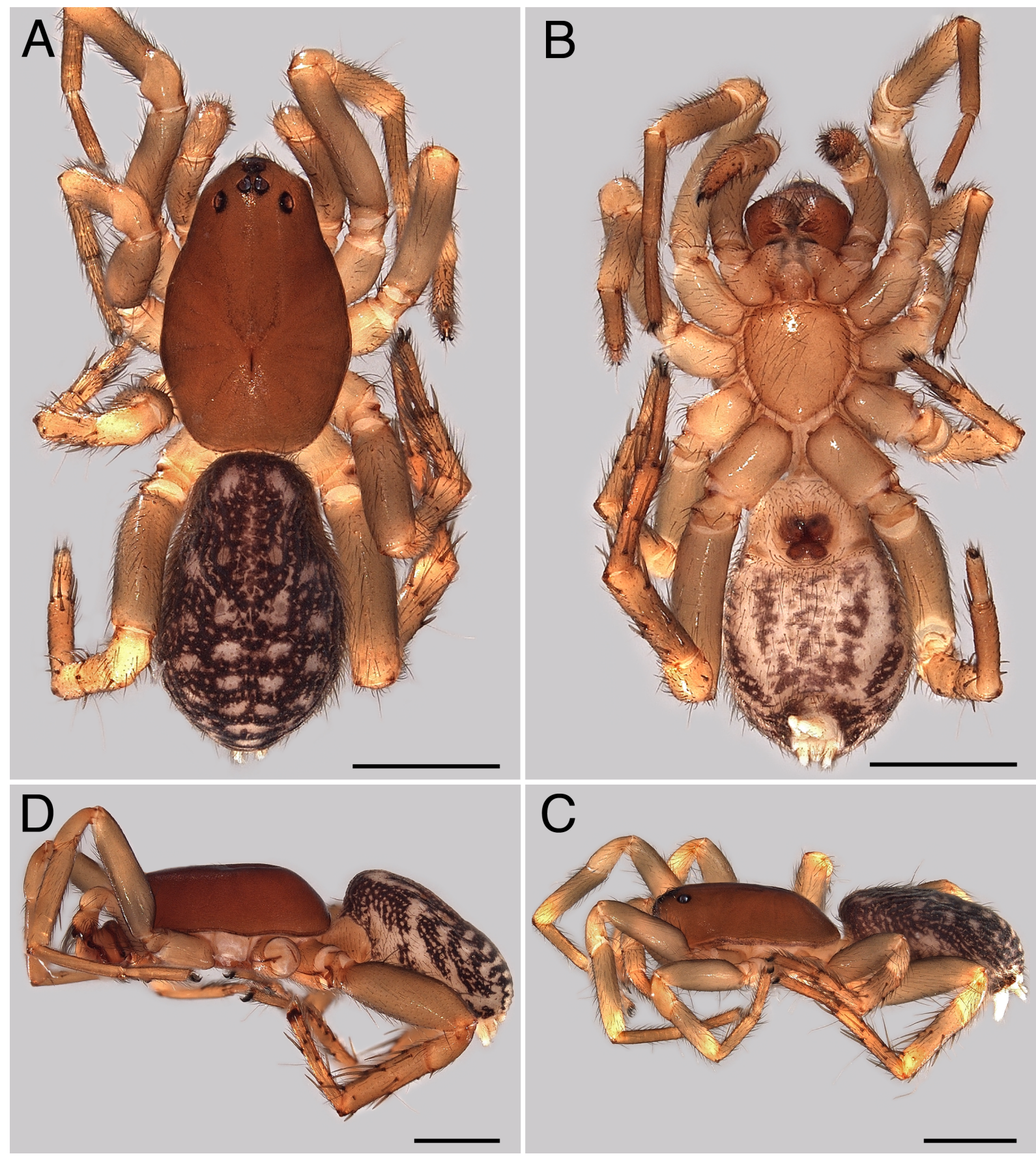

Fig. 2. Ballomma erasmus gen. et sp. nov. A-C. Paratype,, . D. Holotype, $\widehat{\jmath}$. A. Habitus, dorsal view. B. As preceding, ventral view. C. As preceding, lateral view. D. Habitus, lateral view. Scale bars: $1 \mathrm{~mm}$. 
JOCQUÉ R. \& HENRARD A., Ballomma, a new genus in the Zodariidae

\section{Description}

Male (holotype)

Measurements. Total length 4.97; carapace 2.63 long, 0.99 high, 1.85 wide, narrowed to 0.85 in eye region.

Colouration. Carapace (Fig. 1A) medium brown without silvery setae; chelicerae medium brown in basal half, pale brown in distal half, sternum brownish orange (Fig. 1B-C); legs uniform pale yellowish brown, femora with greenish tinge; abdomen (Fig. 1A-B, D): dorsum and sides pale with complex dark pattern; venter pale, yellowish sclerotized areas in front of spinnerets and in front of epigastric fold; spinnerets pale yellow.

CARAPACE (Figs 1A, 2D). Smooth, strongly narrowed in front; flat, fovea long, in shallow depression. Chilum double, each sclerite 0.05 high, 0.13 wide; no setae. Sternum shield-shaped, 1.07 long, 0.85 wide.

Eyes. AME: 0.08; ALE: 0.11; ALE-ALE: 0.00; AME-ALE: 0.05; PME: 0.10; PLE: 0.12; PME-PME: 0.03; PME-PLE: 0.13 . Clypeus 0.21 or 2.6 times width of ALE, strongly retreating.

LEGS. Anterior tarsi shorter than metatarsi and fusiform; hinged hairs on TI and TII.

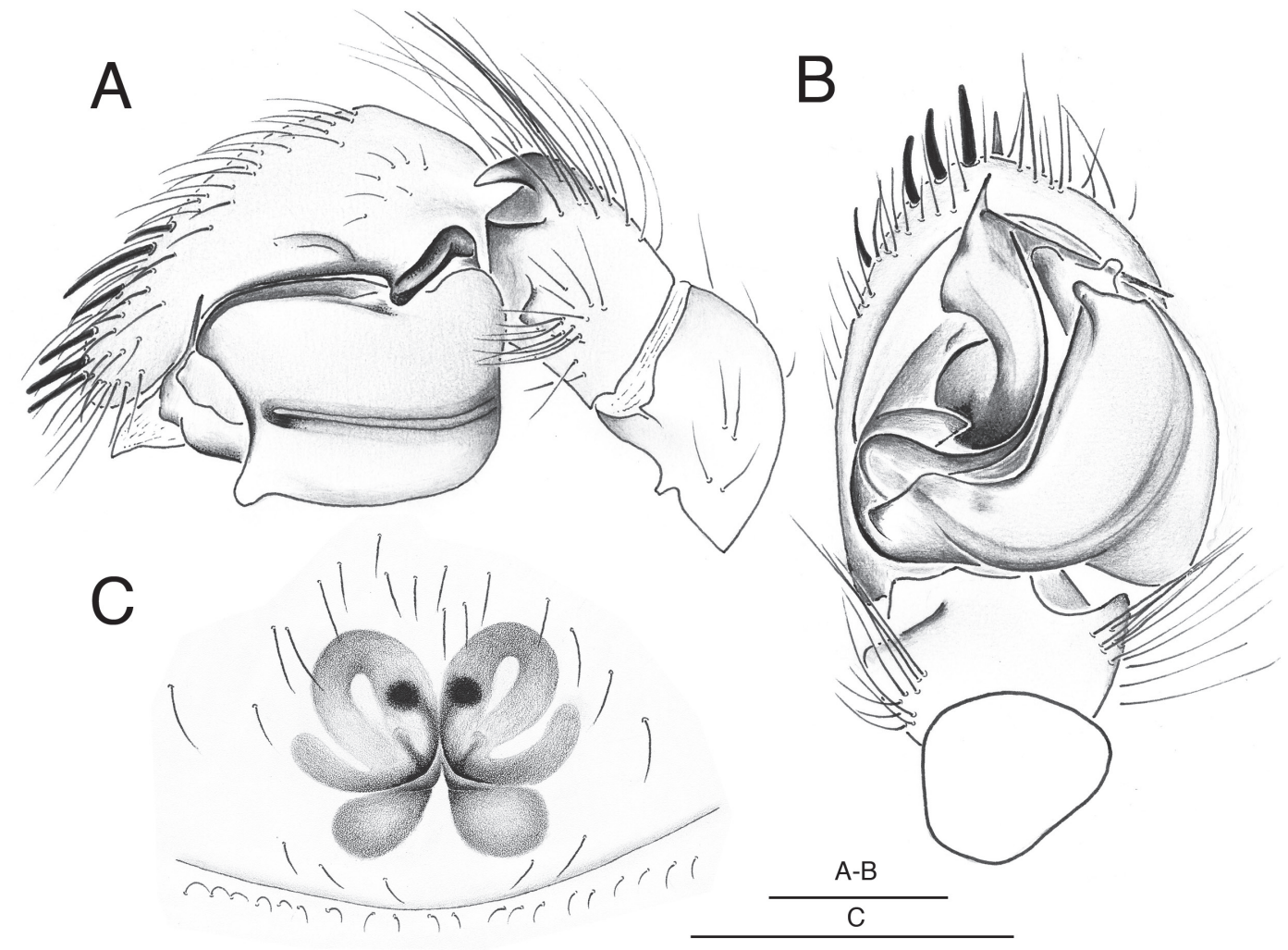

Fig. 3. Ballomma erasmus gen. et sp. nov. A-B. Holotype, o. C. Paratype, + . A. Male palp, retrolateral view. B. As preceding, ventral view. C. Epigyne, ventral view. Scale bars: $0.5 \mathrm{~mm}$. 
European Journal of Taxonomy 163: 1-24 (2015)

SPINATION.

\begin{tabular}{ccccc}
\hline & F & P & T & Mt \\
\hline I & d2 & - & - & v2-2-2 \\
II & $\mathrm{d} 3$ & - & v1 & v2-2dw3 \\
III & d2 & d1rl1 & p12d3rl2v2-2-2 & 6dispdw5 \\
IV & d2 & d1rl1 & p14d3rl3v2-2-2 & 8dispdw5 \\
\hline
\end{tabular}

LEG MEASUREMENTS.

\begin{tabular}{ccccccc}
\hline & $\mathrm{F}$ & $\mathrm{P}$ & $\mathrm{T}$ & $\mathrm{Mt}$ & $\mathrm{t}$ & total \\
\hline $\mathrm{I}$ & 1.61 & 0.63 & 1.26 & 1.19 & 0.77 & 5.46 \\
II & 1.33 & 0.63 & 0.84 & 1.05 & 0.56 & 4.41 \\
III & 1.33 & 0.63 & 0.70 & 0.91 & 0.56 & 4.13 \\
IV & 1.68 & 0.77 & 1.12 & 1.54 & 0.70 & 5.81 \\
\hline
\end{tabular}

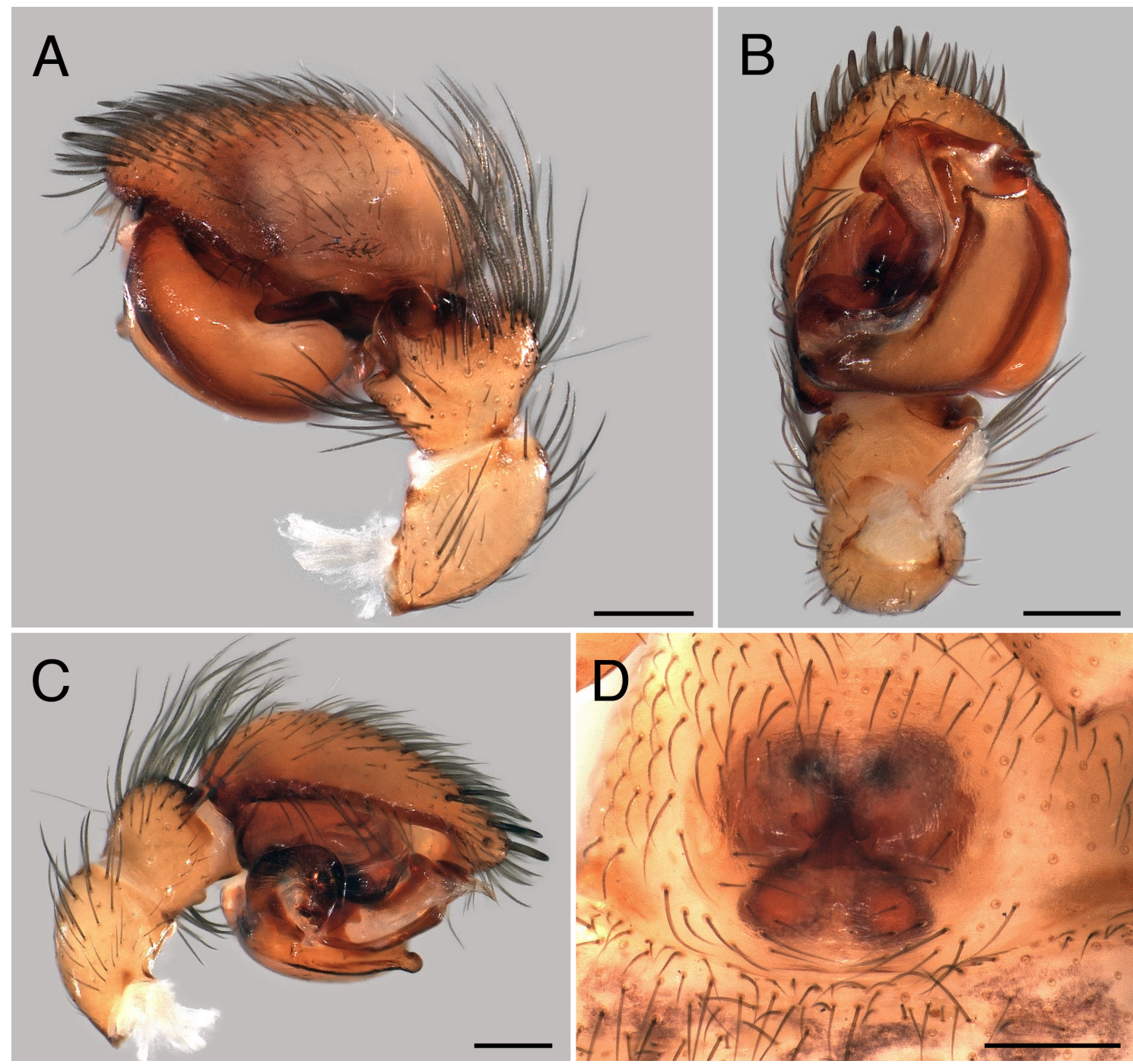

Fig. 4. Ballomma erasmus gen. et sp. nov. A-C. Holotype, đ̂. D. Paratype, $q$. A. Male palp, retrolateral, slightly posterior and dorsal, view. B. As preceding, ventral view. C. As preceding, prolateral view. D. Epigyne, ventral view. Scale bars: $0.2 \mathrm{~mm}$. 
JOCQUÉ R. \& HENRARD A., Ballomma, a new genus in the Zodariidae

Abdomen (Figs $1 \mathrm{~A}-\mathrm{B}, \mathrm{D}, 2 \mathrm{D})$ ). Area in front of epigastric fold with 15 small spines. Spinnerets as for genus.

MALE PALP (Figs 3A-B, 4A-C). Femur with long ventral setae in distal half; patella without boss; tibia with tuft of long setae along distal dorsal margin; RTA with short sharp hook dorsolaterally, lateral and ventrolateral knobs; cymbium with large curved retrolateral basal flange, seven distal, truncated spines; subtegulum with three curved ridges; tegulum large, distal extremity with ventral knob and dorsal flange; sperm duct conspicuous, slightly sinuous.

Female (paratype together with holotype)

MeAsuRements. Total length 4.47; carapace 2.06 long, 1.28 wide, 0.71 high, narrowed to 0.85 in eye region.

Colouration. Carapace (Fig. 2A, C) medium brown with dark margin and faintly delimited triangle suffused with black in front of fovea; chelicerae (Fig. 2B) medium brown; legs and sternum yellow; abdomen (Fig. 2A-C): dorsum and sides dark sepia with complex pale pattern; venter pale with few darker spots; spinnerets yellow.

CARAPACE. Smooth. Clypeus with dispersed setae. Chilum poorly delimited. Sternum shield-shaped, 0.92 long, 0.71 wide.
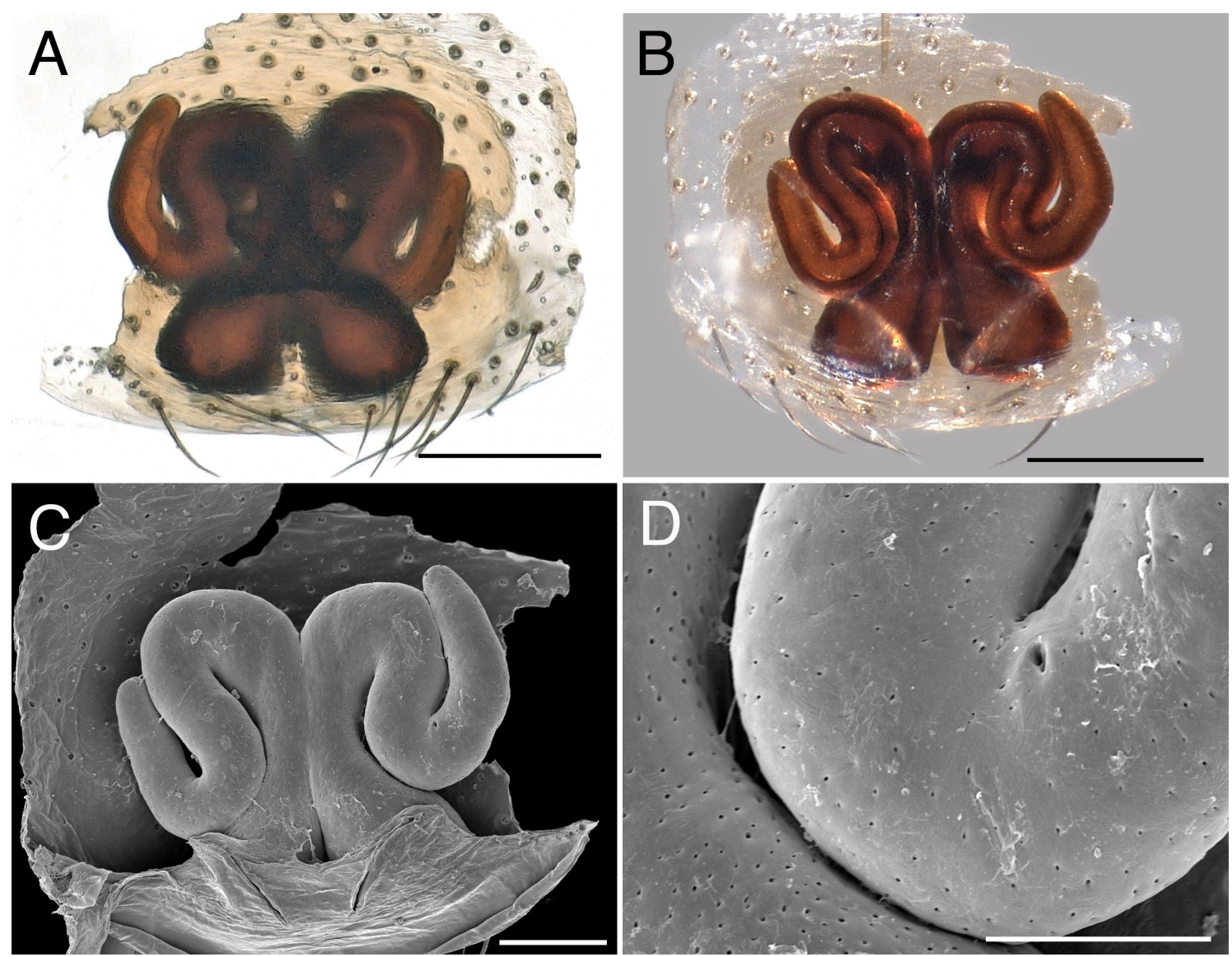

Fig. 5. Ballomma erasmus gen. et sp. nov. Paratype, ․ A. Epigyne, cleared, ventral view. B. As preceding, dorsal view. C. Epigyne, SEM, dorsal view. D. As preceding, detail. Scale bars: A-B = $0.2 \mathrm{~mm} ; \mathrm{C}=0.1 \mathrm{~mm} ; \mathrm{D}=50 \mathrm{~mm}$. 
Eyes. AME: 0.07; ALE: 0.10; ALE-ALE: 0.0; AME-ALE: 0.04; PME: 0.08; PLE: 0.12; PMEPME: 0.03; PME-PLE: 0.10 . Clypeus 0.15 or 2.0 times width of ALE; slightly retreating.

LEGS. No hinged hairs; preening brush on II-IV poorly developed.

SPINATION.

\begin{tabular}{ccccc}
\hline & F & P & T & Mt \\
\hline I & d1 & - & - & - \\
II & d1 & - & v1 & - \\
III & d1 & - & pl2d2rl2v1-2-2 & 6disp dw6 \\
IV & d1 & - & pl2d3rl2v1-2-2 & 8disp dw6 \\
\hline
\end{tabular}

LEG MEASUREMENTS.

\begin{tabular}{ccccccc}
\hline & $\mathrm{F}$ & $\mathrm{P}$ & $\mathrm{T}$ & $\mathrm{Mt}$ & $\mathrm{t}$ & total \\
\hline I & 1.19 & 0.49 & 0.98 & 0.84 & 0.63 & 4.13 \\
II & 1.05 & 0.49 & 0.70 & 0.70 & 0.49 & 3.43 \\
III & 0.77 & 0.42 & 0.56 & 0.70 & 0.49 & 2.94 \\
IV & 1.26 & 0.63 & 0.98 & 1.19 & 0.70 & 4.76 \\
\hline
\end{tabular}

PALP. Triangular (Fig. 2B), slightly flattened ventrally, with row of prolateral short spines; claw with three teeth, not turned inward.

EPIGYNe (Figs 3C, 4D, 5A-D). Roughly quadrangular; anterior ducts clearly visible, S-shaped disrupting the X-shape; spermathecae fairly small separated by about half their distance.

\section{Distribution}

Only known from the type locality in the Limpopo Province, South Africa (Fig. 14).

Ballomma haddadi gen. et sp. nov. urn:1sid:zoobank.org:act:20DEADCF-E2D1-47AA-AC36-29DF62B1A304

Figs $6 \mathrm{~A}-\mathrm{F}, 7 \mathrm{~A}-\mathrm{C}, 8 \mathrm{~A}-\mathrm{D}, 14$

\section{Diagnosis}

The male of $B$. haddadi gen. et sp. nov. is easily recognized by the peculiar palp with the long, thin, sinuous embolus provided at its base with a large, sharp process pointing forward. The female has a characteristic epigyne with dark central area from where procurved cul-de-sac tubes originate, followed by well-separated spermathecae.

\section{Etymology}

The species name is a patronym in honor of Charles Haddad for his many contributions on African arachnology.

\section{Type material}

Holotype

SOUTH AFRICA: $\widehat{\jmath}$, Transvaal (now Limpopo Province), Pietersburg District, Woodbush Forest, 235' S 29²7’ E, Sep. 1960, Leleup N. (MRAC 132646)

\section{Other material examined}

SOUTH AFRICA: 2 우, Transvaal, Lydenburg District, Ohrigstad, 245ㅇ' S 30²0’ E, 27 Mar. 1962, in forest litter, Leleup N. (MRAC 132641). 
JOCQUÉ R. \& HENRARD A., Ballomma, a new genus in the Zodariidae

\section{Description}

Male (holotype)

MeAsurements. Total length 5.47; carapace 2.84 long, 1.78 wide, narrowed to 0.92 in eye region.

Colour. Carapace (Fig. 6A) medium brown without silvery setae; chelicerae, sternum and posterior leg pairs brownish orange (Fig. 6B); anterior leg pairs yellowish orange; abdomen (Fig. 6A-B): dorsum and sides grey with complex pale pattern; venter pale with faint grey pattern, yellow in front of epigastric furrow; spinnerets yellow.

CARAPACE. Reticulated; flat, profile without dip. Chilum double, each sclerite 0.07 high, 0.07 wide; no setae. Sternum shield-shaped, 0.92 long, 0.71 wide.
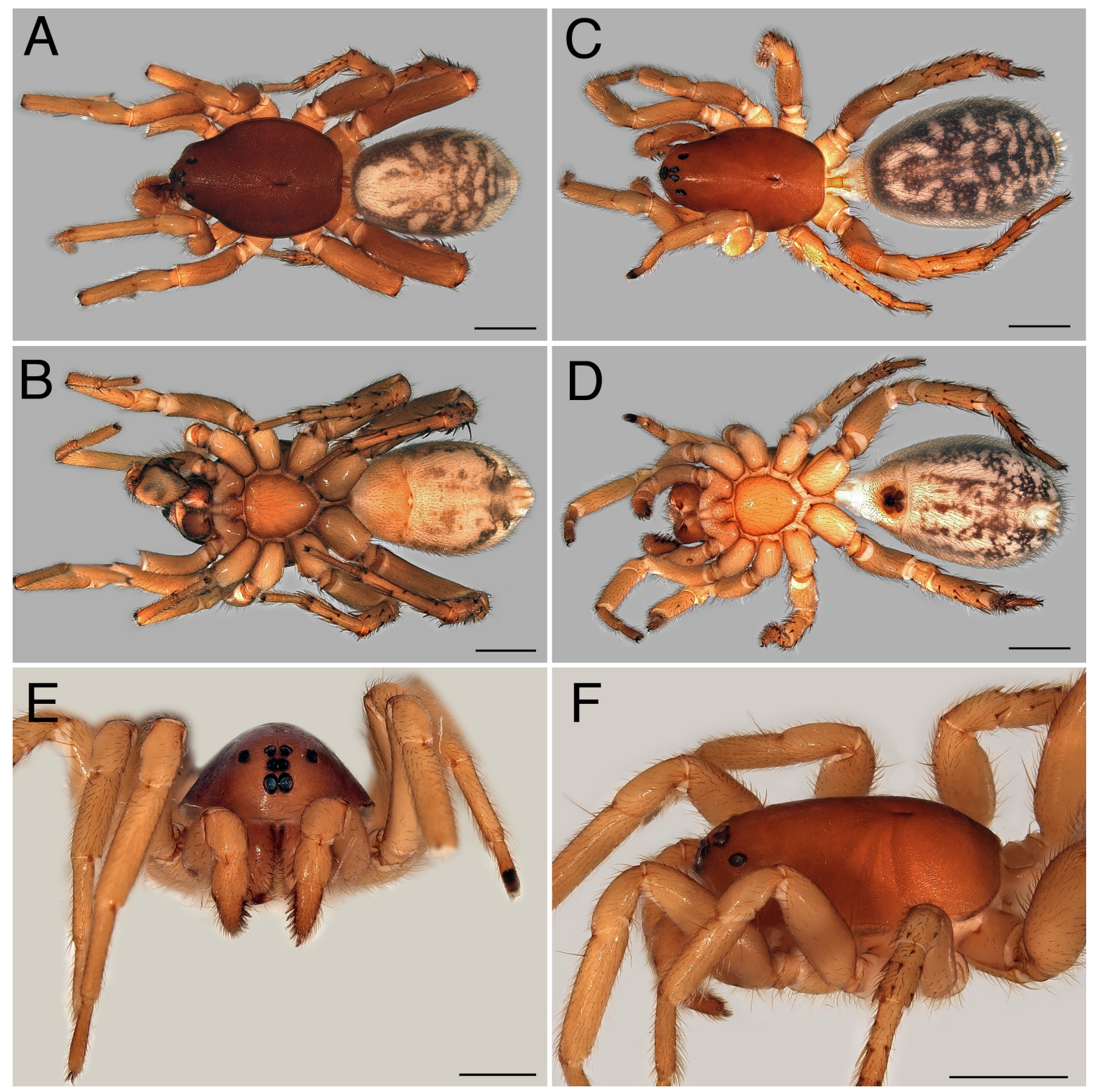

Fig. 6. Ballomma haddadi gen. et sp. nov. A-B. Holotype, ô. C-F. o (MRAC 132641). A. Habitus, dorsal view. B. As preceding, ventral view. C. Habitus, dorsal view. D. As preceding, ventral view. E. Prosoma, frontal view. F. Prosoma, dorsolateral view. Scale bars: $1 \mathrm{~mm}$. 
Eyes. AME: 0.07; ALE: 0.13; ALE-ALE: 0.00; AME-ALE: 0.05; PME: 0.12; PLE: 0.13; PMEPME: 0.05; PME-PLE: 0.18. Clypeus 0.38 or 2.9 times width of ALE.

LEGS. Without hinged hairs.

SPINATION.

\begin{tabular}{ccccc}
\hline & F & P & T & Mt \\
\hline I & d1 & - & v2-1 & v1-2-1 \\
II & d1 & - & v1-1-2 & v2-2-2 \\
III & d1 & rl1 & pl2d3rl2v2-2-2 & 10ispdw6 \\
IV & d2 & d1rl1 & pl3d3rl3v2-2-2 & 14dispdw6 \\
\hline
\end{tabular}

LEG MEASUREMENTS.

\begin{tabular}{ccccccc}
\hline & $\mathrm{F}$ & $\mathrm{P}$ & $\mathrm{T}$ & $\mathrm{Mt}$ & $\mathrm{t}$ & total \\
\hline I & 1.68 & 0.70 & 1.40 & 1.19 & 0.91 & 5.88 \\
II & 1.40 & 0.63 & 0.91 & 0.91 & 0.63 & 4.48 \\
III & 1.26 & 0.77 & 0.63 & 0.91 & 0.56 & 4.13 \\
IV & 2.10 & 0.84 & 1.12 & 1.40 & 0.77 & 6.23 \\
\hline
\end{tabular}

ABDOMEN. Epiandrum well developed with oval membranous patch with two comma shaped marks along posterior margin and two tiny darker spots along frontal margin.

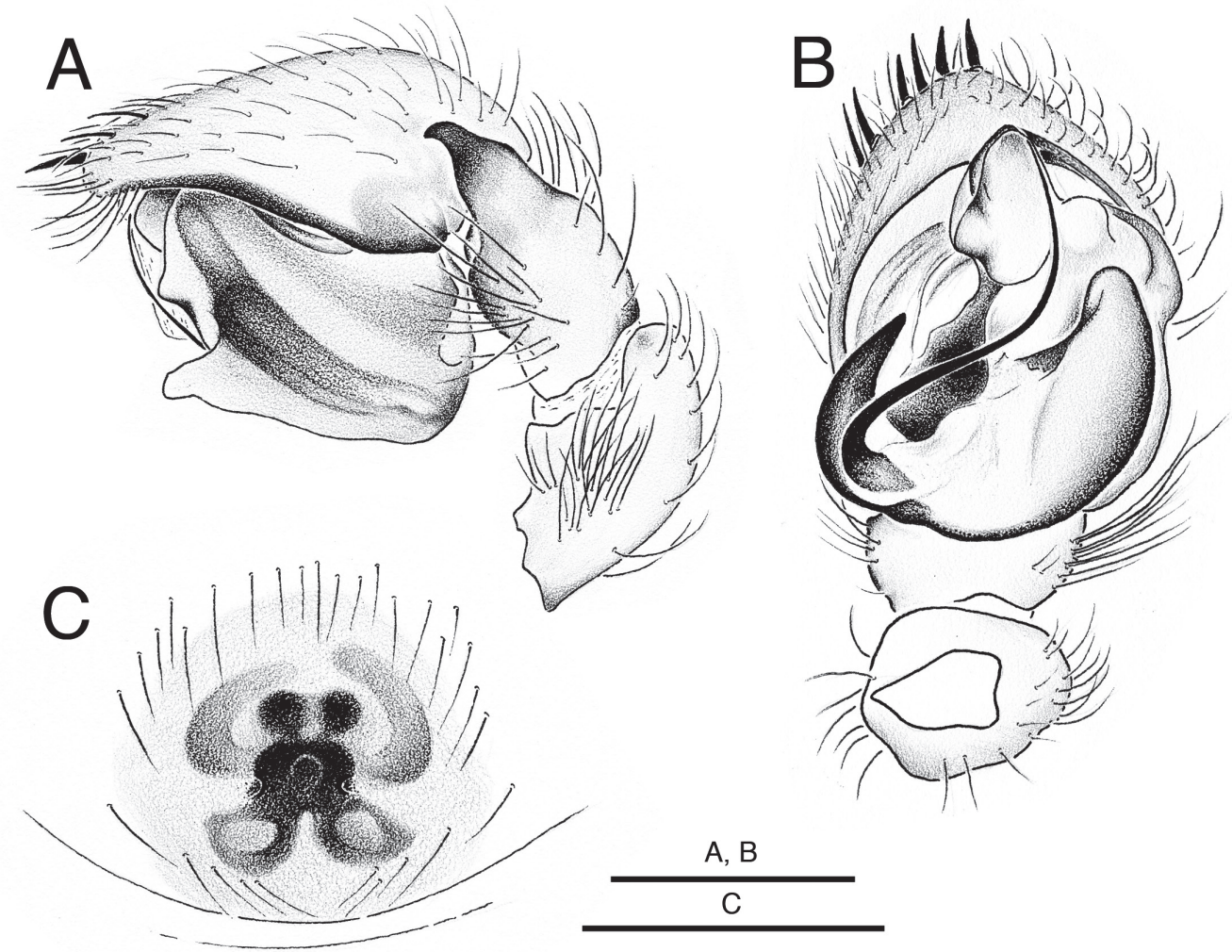

Fig. 7. Ballomma haddadi gen. et sp. nov. A-B. Holotype, O̊. C. $q$ (MRAC 132641). A. Male palp, retrolateral view. B. As preceding, ventral view. C. Epigyne, ventral view. Scale bars: $0.5 \mathrm{~mm}$. 
Male palp (Figs 7A-B, 8A-B). Patella with pro- and retrolateral hair tufts. tibia with dorsolateral apophysis, roughly triangular and pointed, retrolaterally concave; cymbium with basolateral slightly indented protrusion, seven distolateral spines; tegulum high, in the middle with retrolateral protrusion with rounded tip; distally with membranous part ending in long, sickle-shaped apophysis (could be homologous to MA); embolus originating on posterior part of tegulum, thin, slender, curved over central part of tegulum, with large sickle-shaped sclerite at base.

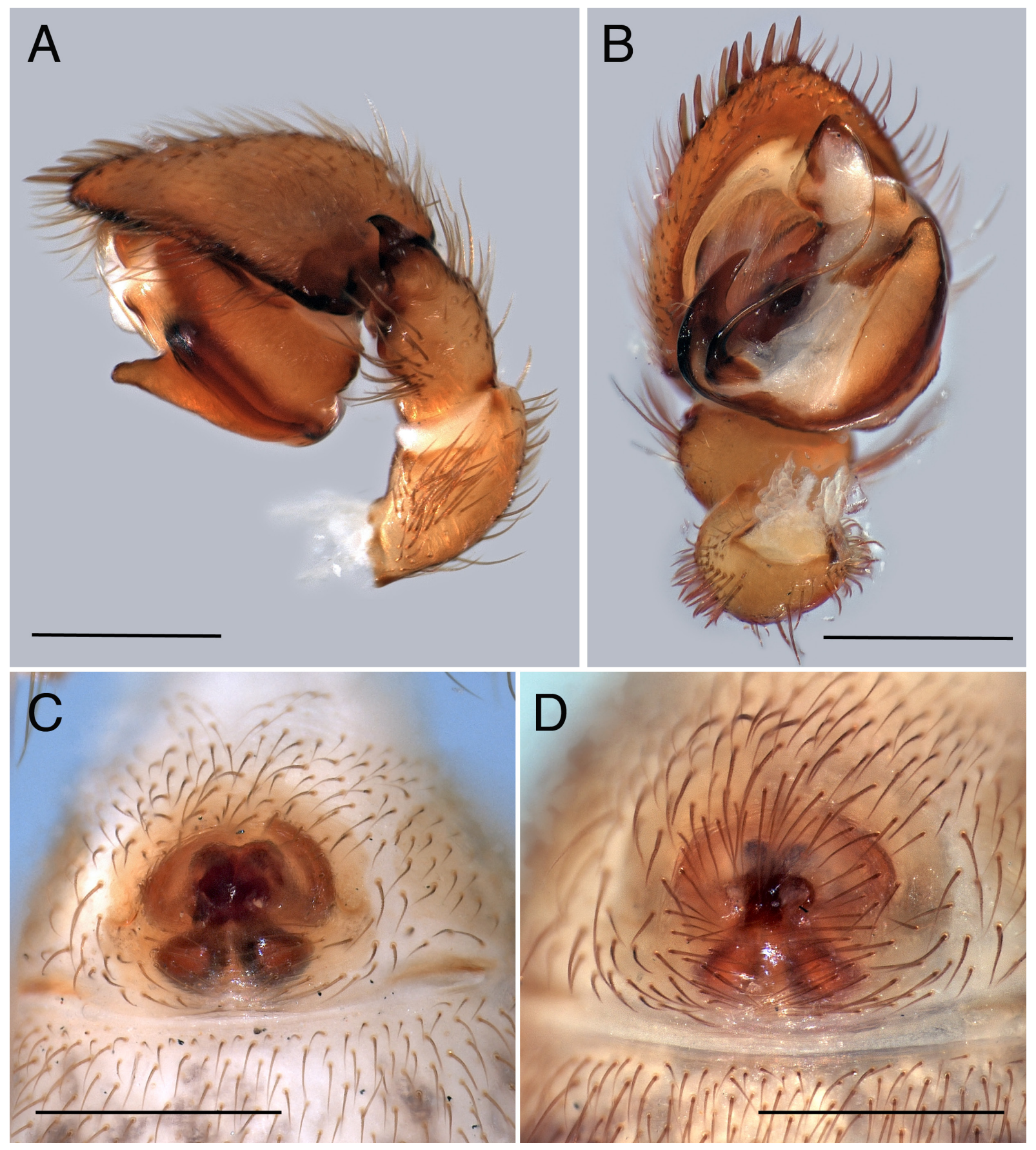

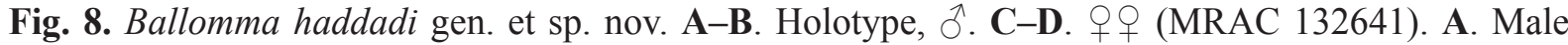
palp, retrolateral view. B. As preceding, ventral view. C. Epigyne, ventral view. D. As preceding, other specimen. Scale bars: $0.5 \mathrm{~mm}$. 
Female (largest of additional material)

MesuremENTs. Total length 7.46; carapace 3.34 long, 2.13 wide, narrowed to 0.92 in eye region.

Colour. Carapace (Fig. 6C-F) pale orange brown; chelicerae, sternum and legs yellowish; abdomen (Fig. 6C-D): dorsum and sides grey with complex dark pattern; venter pale with faint grey pattern, spinnerets pale yellow.

CARAPace. Smooth. Clypeus with dispersed setae. Chilum double, each sclerite 0.07 high, 0.10 wide; no setae. Sternum shield-shaped, 1.28 long, 1.14 wide.

Eyes. AME: 0.09; ALE: 0.13; ALE-ALE: 0; AME-ALE: 0.02; PME: 0.11; PLE: 0.12; PME-PME: 0.07; PME-PLE: 0.26 . Clypeus 0.33 or 3.6 times width of ALE.

LEGS. Hinged hairs absent.

SPINATion.

\begin{tabular}{ccccc}
\hline & F & P & T & Mt \\
\hline I & d2 & - & - & - \\
II & d2 & - & v1-1-1 & $2-2-2$ \\
III & d2 & d1rl1 & pl3d3rl3v1-2-2 & 8disp dw6 \\
IV & d2 & d1rl1 & pl3d3rl3v2-3-2 & 9disp dw6 \\
\hline
\end{tabular}

LEG MEASUREMENTS.

\begin{tabular}{ccccccc}
\hline & $\mathrm{F}$ & $\mathrm{P}$ & $\mathrm{T}$ & $\mathrm{Mt}$ & $\mathrm{t}$ & total \\
\hline I & 1.89 & 0.84 & 1.47 & 1.26 & 0.91 & 6.37 \\
II & 1.40 & 0.77 & 0.98 & 0.98 & 0.70 & 4.83 \\
III & 1.40 & 0.70 & 0.77 & 0.84 & 0.77 & 4.48 \\
IV & 1.96 & 0.91 & 1.40 & 1.54 & 0.91 & 6.72 \\
\hline
\end{tabular}

PALP (Fig. 6E). Claw with three small teeth; turned inward over $<30^{\circ}$. Tarsus triangular with ventral side flat, provided with 10 prolateral, four retrolateral spines.

EpigYNe (Figs 7C, 8C-D). Flat, poorly sclerotized area, with internal structure and cul-de-sac tubes visible in transparency.

\section{Distribution}

Known from the Limpopo Province in South Africa (Fig. 14).

Ballomma legala gen. et sp. nov. urn:1sid:zoobank.org:act:83C81CDA-F2F9-4D16-B8D7-B7CA396043F5

Figs $9 \mathrm{~A}-\mathrm{E}, 10 \mathrm{~A}-\mathrm{D}, 14$

\section{Diagnosis}

The female of B. legala gen. et sp. nov. is easily recognized by the dense field of spinules on the distal part of the endites and the epigyne with V-shaped mark in front of the transverse row of spermathecae. Also juveniles and subadult males have a field of spinules on the endites.

\section{Etymology}

The species name is a noun in apposition taken from the type locality. 
JOCQUÉ R. \& HENRARD A., Ballomma, a new genus in the Zodariidae

\section{Type material}

\section{Holotype}

SOUTH AFRICA: $q$, Limpopo Province, Legalameetse Nature Reserve, Balloon Forest Leg 01, $24^{\circ} 11.966 \mathrm{~S} 30^{\circ} 20.327 \mathrm{E}, 17 \mathrm{Jan} .2009$, riverine to mixed woodland, leaf litter sifting, N. Hahn (NCA 2015/3582).

\section{Paratype}

SOUTH AFRICA: $1 q$, same data as holotype.

\section{Remark}

The tube contains four juveniles and three subadult males, most likely conspecific with the holotype.

\section{Description}

Female (holotype)

MeAsuREMENTS. Total length 5.25; carapace 2.56 long, 0.92 high, 1.63 wide, narrowed to 0.98 in eye region.

Colour. Carapace (Fig. 9A, D) medium brown with thin dark margin; chelicerae medium brown; legs yellowish orange; and sternum yellow (Fig. 9B-C, E); abdomen (Fig. 9A-B, D): dorsum and sides
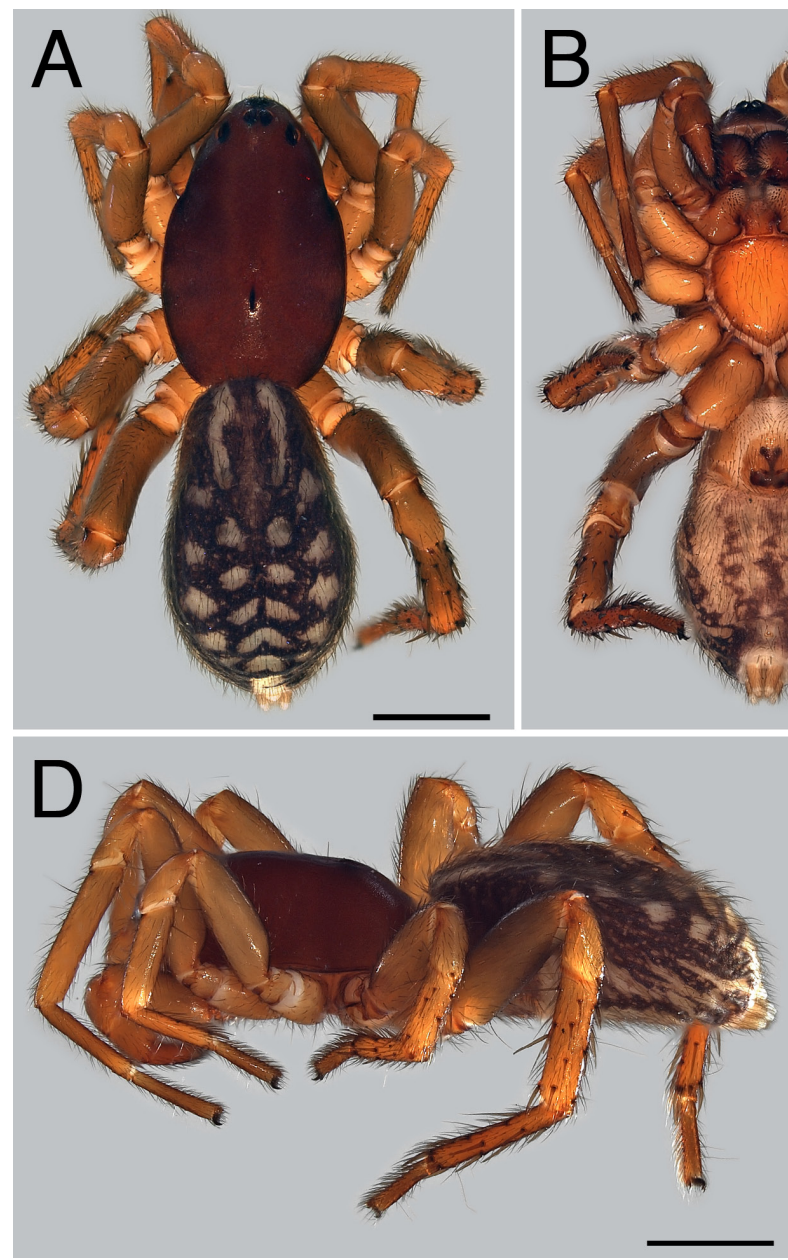
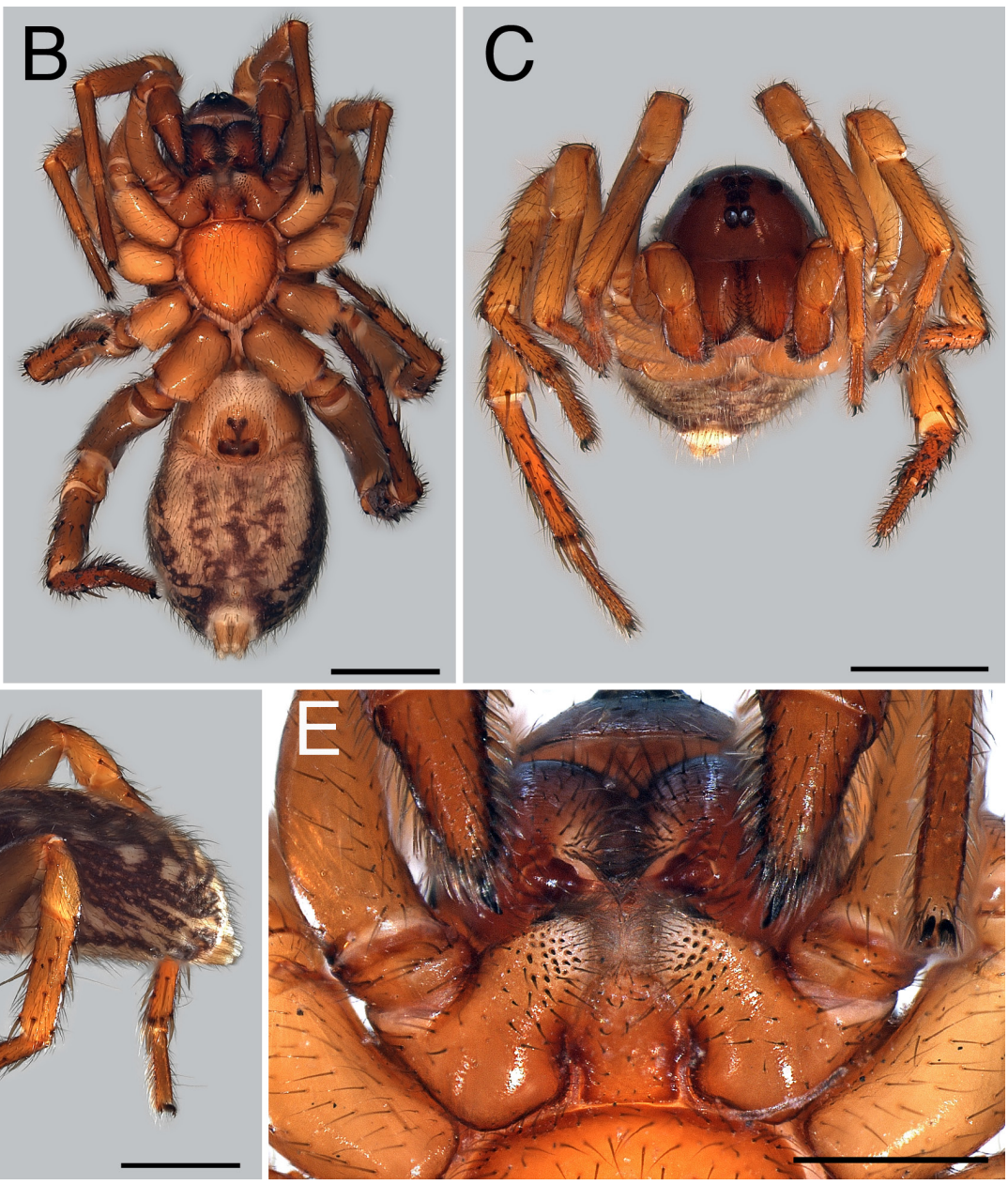

Fig. 9. Ballomma legala gen. et sp. nov. Holotype, ․ A. Habitus, dorsal view. B. As preceding, ventral view. C. As preceding, frontal view. D. As preceding, lateral view. E. Mouth parts, ventral view. Scale bars: $1 \mathrm{~mm}$. 
with complex pale pattern on dark grey background; venter pale with three longitudinal bands of darker mottling; spinnerets yellow.

CARAPACE. Finely reticulate. Clypeus with dispersed setae. Endites with dense field of small spinules in distal half (Fig. 9E). With small crescent-shaped precoxal sclerite at coxae II and III.

Eyes. AME: 0.09; ALE: 0.12; ALE-ALE: 0.0; AME-ALE: 0.04; PME: 0.09; PLE: 0.12; PMEPME: 0.03 ; PME-PLE: 0.15 . Clypeus 0.23 or 1.7 times width of ALE; slightly retreating.

Chilum. Double, each part 0.04 high, 0.12 wide. Sternum shield-shaped, 0.99 long, 0.85 wide.

LEGS. Hinged hair on T I and II; preening brush on II-IV poorly developed.

SPINATION.

\begin{tabular}{ccccc}
\hline & F & P & T & Mt \\
\hline I & d1 & - & - & v1 \\
II & d1 & - & v1-1 & v1-1dw3 \\
III & d2 & d1rl1 & pl2d3rl2v2-2-2 & 8disp dw6 \\
IV & d2 & d1tl1 & pl4d3r13v2-2-2 & 10disp dw6 \\
\hline
\end{tabular}
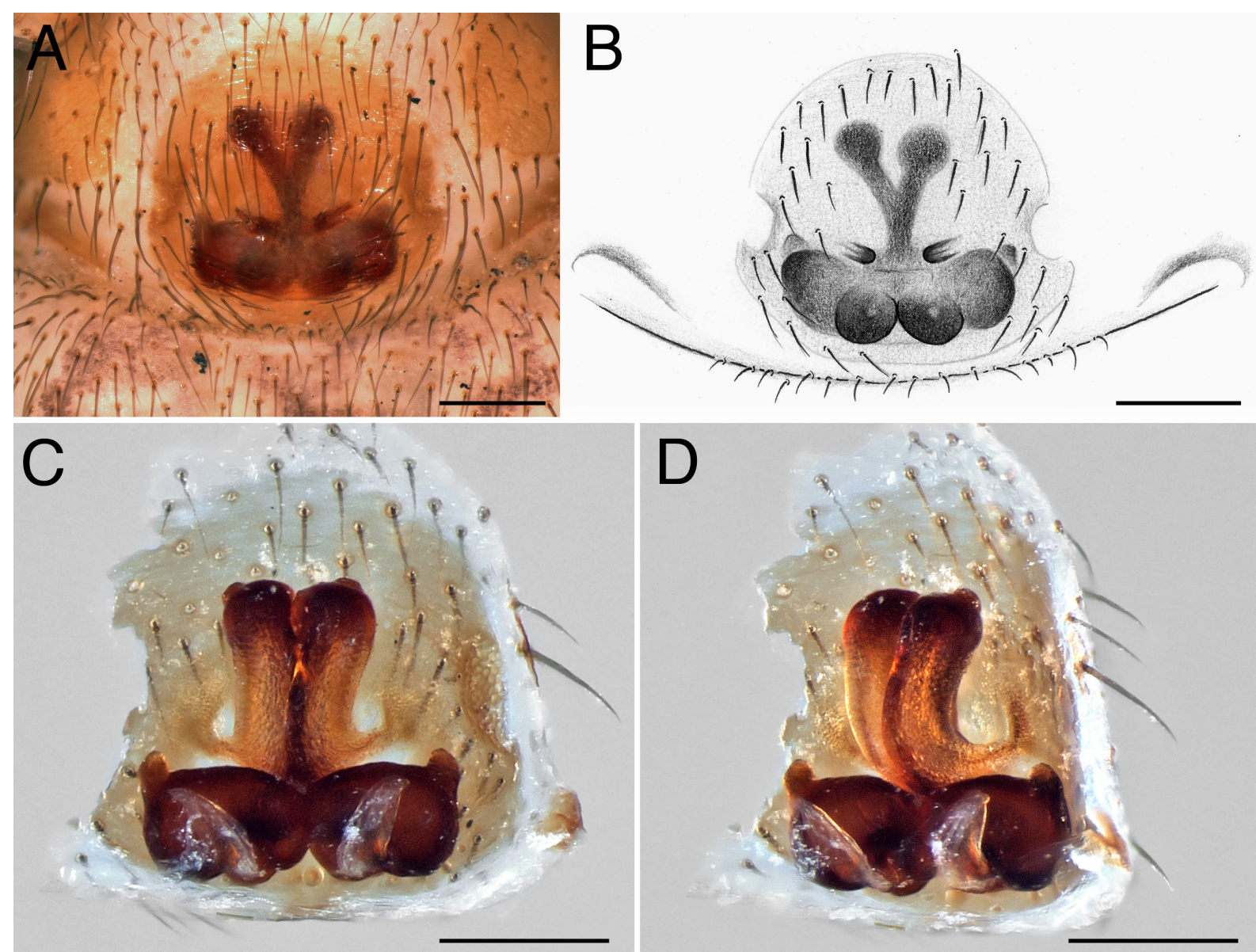

Fig. 10. Ballomma legala gen. et sp. nov. Holotype, ㅇ. A. Epigyne, ventral view. B. As preceding, ventral view. C. Epigyne, digested, dorsal view. D. As preceding, dorsolateral view. Scale bars: $0.2 \mathrm{~mm}$. 
JOCQUÉ R. \& HENRARD A., Ballomma, a new genus in the Zodariidae

LEG MEASUREMENTS.

\begin{tabular}{ccccccc}
\hline & $\mathrm{F}$ & $\mathrm{P}$ & $\mathrm{T}$ & $\mathrm{Mt}$ & $\mathrm{t}$ & total \\
\hline I & 1.40 & 0.70 & 0.84 & 0.91 & 0.70 & 4.55 \\
II & 1.19 & 0.63 & 0.77 & 0.70 & 0.56 & 3.85 \\
III & 1.12 & 0.63 & 0.70 & 0.77 & 0.56 & 3.78 \\
IV & 1.47 & 0.77 & 1.12 & 1.26 & 0.70 & 5.32 \\
\hline
\end{tabular}

PALP. Tarsus triangular, slightly flattened ventrally, with row of prolateral short spines; claw with three teeth, not turned inward.

EPIGYNe (Fig. 10A-D). Roughly quadrangular; anterior ducts clearly visible, forming a V-shaped pattern, followed by transverse row of globular structures.

\section{Distribution}

Only known from the type locality in the Limpopo Province, South Africa (Fig. 14).

Ballomma neethlingi gen. et sp. nov. urn:lsid:zoobank.org:act:A55B7447-0792-4709-8ED2-E639C6B472A7

Figs $11 \mathrm{~A}-\mathrm{E}, 12 \mathrm{~A}-\mathrm{C}, 13 \mathrm{~A}-\mathrm{C}, 14$

\section{Diagnosis}

The male of D. neethlingi gen. et sp. nov. is easily recognized by the field of spines in front of the epigastric fold and the palp with a retrolateral patellar swelling and a broad triangular transparent RTA. The female has a characteristic epigyne in which the ducts in transparency are in the shape of an X with a slight extension where upper and lower parts of $\mathrm{X}$ meet.

\section{Etymology}

The species name is a patronym for Jan Neethling a pseudoscorpion specialist and the collector of the holotype.

\section{Type material}

Holotype

SOUTH AFRICA: 9 , Limpopo Province, Medike Mountain Reserve, 2259’39” S 2936'52” E, 8 Nov. 2012, montane bushveld, sifting litter, J.A. Neethling (NCA 2015/3484; ex MRAC 241635).

Paratype

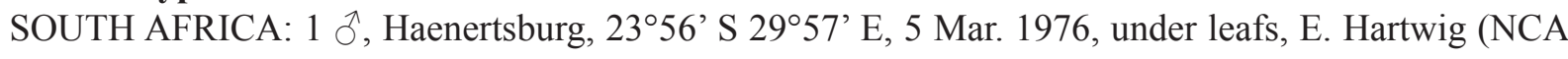
76/1048).

\section{Other material examined}

SOUTH AFRICA: 5 juveniles, same data as holotype.

\section{Description}

Male (paratype)

Measurements. Total length 7.53; carapace 3.34 long, 1.07 high, 2.20 wide, narrowed to 1.07 in eye region.

Colour. Carapace, sternum and chelicerae medium brown without silvery setae (Fig. 11A-C); chelicerae slightly darker at base than in distal half; legs pale yellowish brown; abdomen (Fig. 11A-B): dorsum 
and sides pale with complex dark pattern on dorsum hidden by paler suffusion, provided with four dark apodemes; venter pale with complex dark pattern, yellow sclerotized area in front of epigastric fold; spinnerets pale yellow.

CARAPACE. Smooth (Fig. 11A), strongly narrowed in front; flat, fovea long, in shallow depression. Chilum double, each sclerite 0.05 high, 0.12 wide; no setae. Sternum shield-shaped, 1.35 long, 1.21 wide.

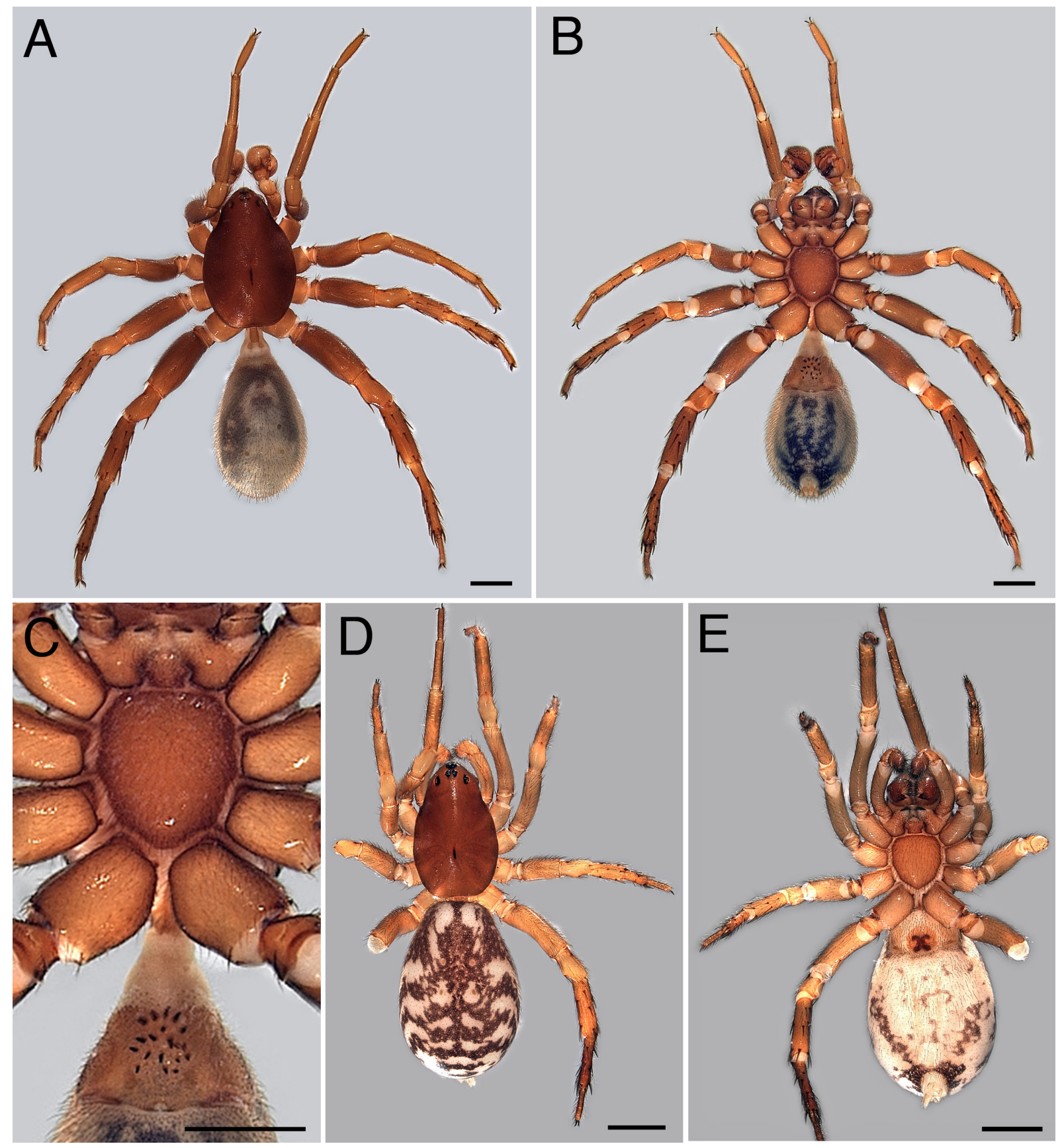

Fig. 11. Ballomma neethlingi gen. et sp. nov. A-C. Paratype, $\widehat{\jmath}$ (NCA 76/1048) D-E. Holotype, $q$. A. Habitus, dorsal view. B. As preceding, ventral view. C. As preceding, detail. D. Habitus, dorsal view. E. As preceding, ventral view. Scale bars: $1 \mathrm{~mm}$. 
JOCQUÉ R. \& HENRARD A., Ballomma, a new genus in the Zodariidae

Eyes. AME: 0.10; ALE: 0.13; ALE-ALE: 0.00; AME-ALE: 0.07; PME: 0.10; PLE: 0.13; PMEPME: 0.07; PME-PLE: 0.18. Clypeus 0.38 or 2.9 times width of ALE, retreating.

LEGS. Anterior tarsi fusiform; no hinged hairs.

SPINATION.

\begin{tabular}{ccccc}
\hline & F & P & T & Mt \\
\hline I & d1 & - & v1-2-2 & v2-2-1 \\
II & d1 & - & v1-2-2 & v2-1-2 \\
III & d2 & d1rl1 & pl2d3r12v2-2-2 & 10disp dw6 \\
IV & d2 & d1rl1 & pl3d3rl3v2-2-2 & 12disp dw6 \\
\hline
\end{tabular}

LEG MEASUREMENTS.

\begin{tabular}{ccccccc}
\hline & $\mathrm{F}$ & $\mathrm{P}$ & $\mathrm{T}$ & $\mathrm{Mt}$ & $\mathrm{t}$ & total \\
\hline I & 2.03 & 0.84 & 1.40 & 1.26 & 1.05 & 6.58 \\
II & 1.33 & 0.77 & 1.12 & 1.12 & 0.77 & 5.11 \\
III & 1.61 & 0.70 & 1.05 & 1.19 & 0.70 & 5.25 \\
IV & 1.75 & 0.70 & 1.47 & 1.75 & 0.91 & 6.58 \\
\hline
\end{tabular}

Aвdomen (Fig. 11A-B). Area in front of epigastric fold with 20 small spines. Spinnerets as for genus.

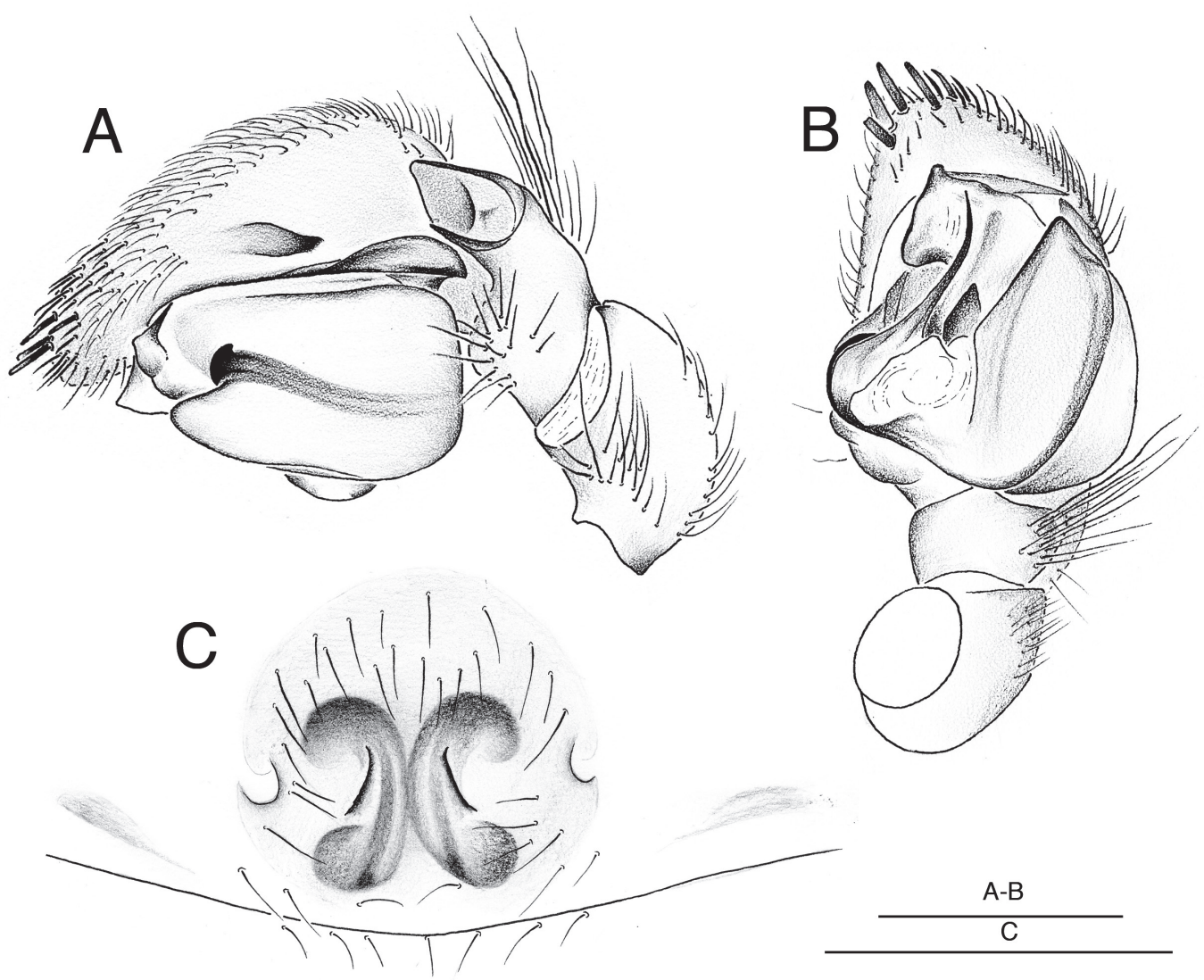

Fig. 12. Ballomma neethlingi gen. et sp. nov. A-B. $\widehat{\jmath}$ (NCA 76/1048) C. Holotype, + . A. Male palp, retrolateral view. B. As preceding, ventral view. C. Epigyne, ventral view. Scale bars: $0.5 \mathrm{~mm}$. 
Male Palp (Figs 12A-B; 13A-B). Patella with small haired ventrolateral swelling; tibia with clusters of hair on dorsal margin and on ventrolateral swelling; RTA roughly triangular, transparent, with rebordered dorsal margin; cymbium densely haired with eight truncated spines near tip; broad, basolateral, folded flange; subtegulum with three ridges and basal notch; tegulum with distoventral protrusion, prolaterally concave accommodating thin, slightly curved embolus; distal part of tegulum with dorsal quadrangular conductor.

Female (holotype)

MeAsuRements. Total length 5.75; carapace 2.41 long, 1.48 wide, 0.92 high, narrowed to 0.71 in eye region.

Colouration. Carapace, chelicerae and sternum brownish orange (Fig. 11D-E); legs brownish yellow; abdomen (Fig. 11D-E): dorsum and sides pale with complex dark pattern; venter pale with few dark spots; spinnerets pale yellow.

CARAPACE (Fig. 11D). Smooth, thinly haired; fovea in shallow depression. Clypeus with dispersed setae. Chilum double, each sclerite 0.07 high, 0.16 wide; no setae. Sternum shield-shaped, 0.99 long, 0.85 wide.

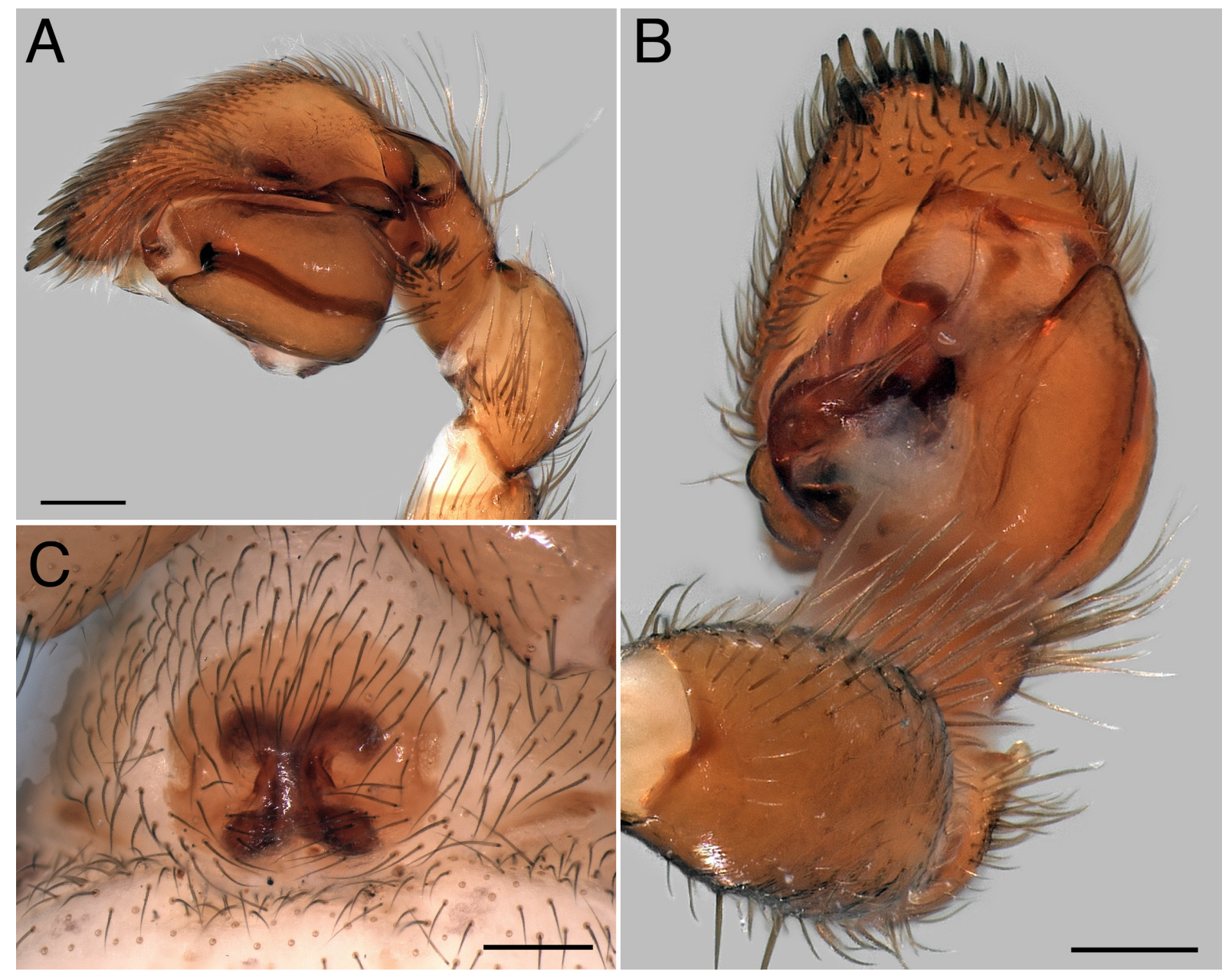

Fig. 13. Ballomma neethlingi gen. et sp. nov. A-B. Paratype, $\widehat{\jmath}$ (NCA 76/1048) C. Holotype,, . A. Male palp, retrolateral view. B. As preceding, ventral view. C. Epigyne, ventral view. Scale bars: $0.2 \mathrm{~mm}$. 
JOCQUÉ R. \& HENRARD A., Ballomma, a new genus in the Zodariidae

Eyes. AME: 0.07; ALE: 0.10;ALE-ALE: 0.0; AME-ALE: 0.0; PME: 0.07; PLE: 0.08; PME-PME: 0.03; PME-PLE: 0.16. Clypeus 0.21 or 3 times width of ALE.

LEGS. Hinged hair on TI and TII.

SPINATion.

\begin{tabular}{ccccc}
\hline & F & P & T & Mt \\
\hline I & d1 & - & - & v1 \\
II & d1 & - & v1-1 & v1-1-2 \\
III & d1 & d1rl1 & pl2d2rl2v1-2-2 & 6disp dw6 \\
IV & d1 & d1rl1 & pl2d3r12v1-1-2 & 10disp dw6 \\
\hline
\end{tabular}

LEG MEASUREMENTS.

\begin{tabular}{ccccccc}
\hline & $\mathrm{F}$ & $\mathrm{P}$ & $\mathrm{T}$ & $\mathrm{Mt}$ & $\mathrm{t}$ & total \\
\hline $\mathrm{I}$ & 2.03 & 0.84 & 1.40 & 1.26 & 1.05 & 6.58 \\
$\mathrm{II}$ & 1.33 & 0.77 & 1.12 & 1.12 & 0.77 & 5.11 \\
III & 1.61 & 0.70 & 1.05 & 1.19 & 0.70 & 5.25 \\
IV & 1.75 & 0.70 & 1.47 & 1.75 & 0.91 & 6.58 \\
\hline
\end{tabular}

Palp with tarsus triangular and ventrally flat; provided with many prolateral and few retrolateral spines; pectinated claw turned inward over $>30^{\circ}$.

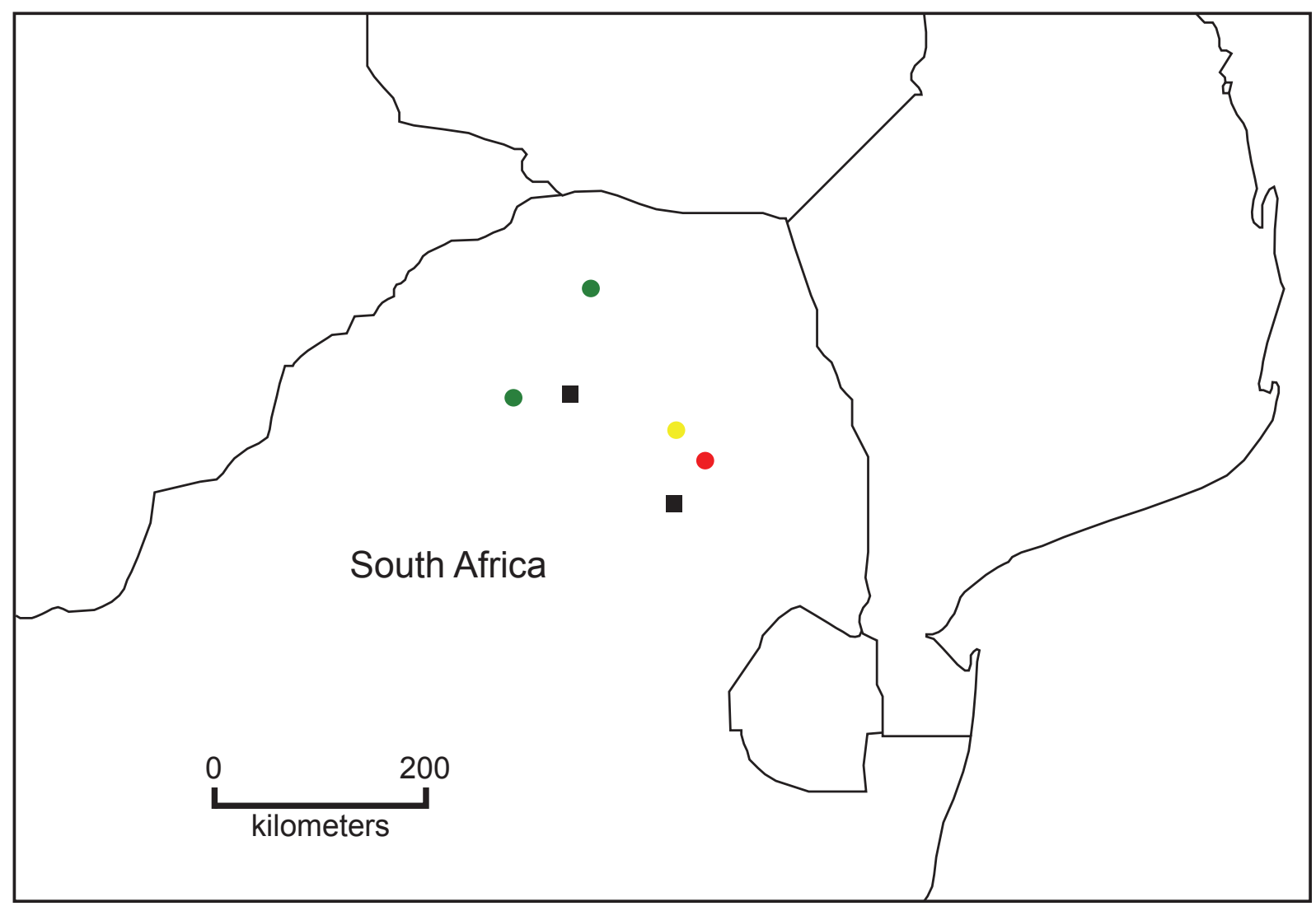

Fig. 14. Distribution of species of Ballomma gen. nov.: B. erasmus gen. et sp. nov. (๑), B. haddadi gen.

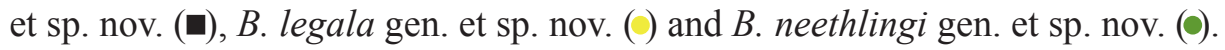


EpIGYNe (Figs 12C, 13C). Roughly rounded area with ducts visible in transparency forming X-shaped pattern, slight extension where top and bottom parts meet.

\section{Distribution}

Known from the Limpopo Province in the northern part of South Africa (Fig.14).

\section{Discussion}

Most genera in the Zodariidae have a fairly large distribution area. This is partly due to the fact that the family has escaped far-reaching splitting. Genera do indeed remain largely subjective systematic levels and whether the species-groups are deeply split or not, makes an evident difference for their distribution. In general, genera are far too small (see Jocqué et al. 2013) thus obscuring patterns of evolution and distribution. But in the Zodariidae, most genera are fairly well delimited on the base of somatic characters which makes the grouping plausible and has prevented unnecessary splitting on the base of genitalic divergence (Jocqué 1990, 2009; Nzigidahera et al. 2011). Only genera with an apparent relictual distribution, like Suffrica Henrard \& Jocqué, 2015, tend to have smaller distribution areas. This probably also applies to Ballomma gen. nov., which turns out to sit near the base of genealogic tree of the Zodariidae (unpublished). A prediction of the genus' distribution (Fig. 15) on the base of climatic data (DIVA-GIS 2011) expects a much larger distribution area than presently known in South Africa, overflowing in Botswana, Zimbabwe and Mozambique. Predictions on the base of climatic data for

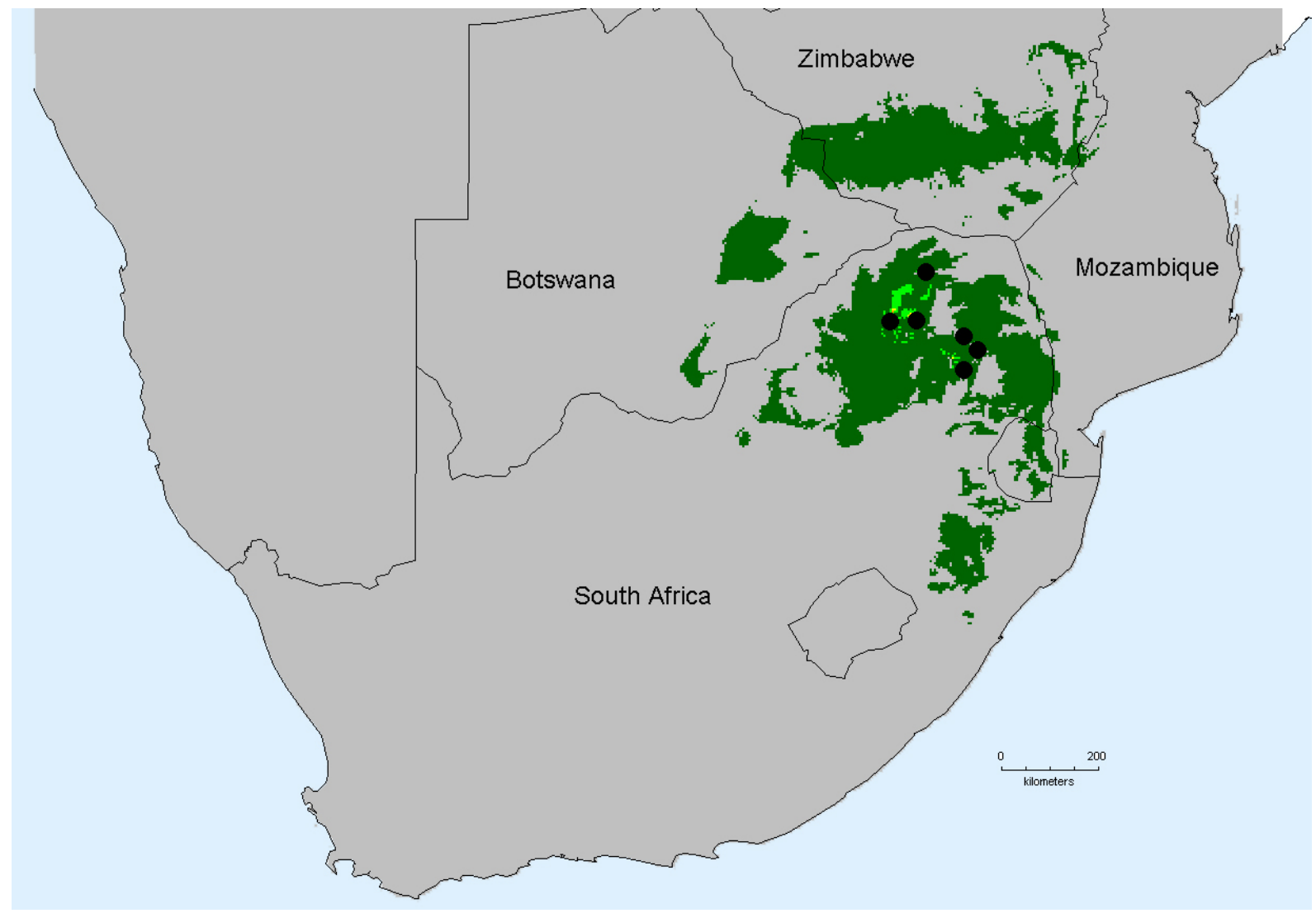

Fig. 15. Predicted distribution of Ballomma gen. nov. calculated in DIVA-GIS on the base of all climatic data as default in the software. Black dots present known localities of Balloma gen. nov. Dark green areas have expected occurrence with the 5-95 percentile; pale green with 2.5-97.5 percentile. 
JOCQUÉ R. \& HENRARD A., Ballomma, a new genus in the Zodariidae

other zodariid genera have shown that areas are sometimes largely overestimated because the calculation cannot take geographical barriers into account. Mallinella Strand, 1906, for instance, is expected to have a large area on Madagascar (unpublished data), but is not present there probably because it was unable to reach the island. The influence of geographical barriers is expected to be particularly important for those genera that occur in habitats that are likely to be disrupted like mountain forest which is apparently preferred by the species of Ballomma gen. nov.

Species with the anterior lateral eyes touching have so far only been found in Ballomma gen. nov. and in Aschema, endemic to Madagascar. The apparent endemicity of Ballomma gen. nov. to a few highlands in the Limpopo Province and their affinities with endemics from Madagascar emphasizes the special character of these habitats and the fact that they are inhabited by taxa from old evolution lines. Further inventories of these montane forest patches might reveal the presence of more taxa representing old evolution lines and makes the study of these mountains a priority for the SANSA project.

\section{Acknowledgements}

We are indebted to Ansie Dippenaar-Schoeman, Robin Lyle, Petro Marais for the loan of type material. We thank Alain Reygel for the drawings. This paper is publication BRC 345 of the Biodiversity Research Center (Université Catholique de Louvain). This work was supported by the FRIA (Fonds pour la Formation à la Recherche dans l'Industrie et dans l'Agriculture).

\section{References}

Dippenaar-Schoeman A., Haddad C.R., Foord S.H., Lyle R., Lotz L.N. \& Marais P. 2015. South African National Survey of Arachnida (SANSA): current status, significant constraints and future needs for documenting arachnid diversity (Arachnida: Araneae). Transactions of the Royal Society of South Africa 70: 1-31. http://dx.doi.org/10.1080/0035919X.2015.1088486

Hijmans R.J., Guarino L. \& Mathur P. 2011.DIVA-GIS. Version 7.5.0.0. Available from http://www. diva-gis-org [accessed on 10 DEC. 2015]

Foord S.H., Mafadza M.M., Dippenaar-Schoeman A. \& Van Rensburg B.J. 2008. Micro-scale heterogeneity of spiders (Arachnida: Araneae) in the Soutpansberg, South Africa: a comparative survey and inventory in representative habitats. African Zoology 43: 156-174. http://dx.doi.org/10.3377/1562$\underline{7020-43.2 .156}$

Jocqué R. 1990. A revision of the Afrotropical genus Diores (Araneae, Zodariidae). Annales du Musée royal de l'Afrique Centrale (Zoologie) 260: 1-81.

Jocqué R. 1991. A generic revision of the spider family Zodariidae (Araneae). Bulletin of the American Museum of Natural History 201: 1-160.

Jocqué R. 2008. A new candidate for a Gondwanaland distribution in the Zodariidae (Araneae): Australutica in Africa. ZooKeys 1: 59-66. http://dx.doi.org/10.3897/zookeys.1.10

Jocqué R. 2009. Some keep it short: on the radiation in the Afrotropical spider genera Capheris and Systenoplacis (Araneae, Zodariidae) without male pedipalp complexity increase. Journal of Afrotropical Zoology 5: 77-148.

Jocqué R. Alderweireldt M. \& Dippenaar-Schoeman A. 2013. Biodiversity, an African perspective. In: Penney D. (ed.) Spider research in the 21st century: 18-57. Siri Scientific press, Rochdale (UK).

Jocqué R. \& Henrard A. 2015. The new spider genus Palindroma, featuring a novel synapomorphy for the Zodariidae (Araneae). European Journal of Taxonomy 152: 1-33. http://dx.doi.org/10.5852/ ejt.2015.152 
Nzigidahera B., Desnyder W. \& Jocqué R. 2011. An overview of the Afrotropical species of Mallinella (Araneae, Zodariidae) with the description of a remarkable new species from Burundi. Journal of Afrotropical Zoology 7: 19-27.

Manuscript received: 20 September 2015

Manuscript accepted: 26 November 2015

Published on: 15 December 2015

Topic editor: Koen Martens

Desk editor: Kristiaan Hoedemakers

Printed versions of all papers are also deposited in the libraries of the institutes that are members of the EJT consortium: Muséum national d'Histoire naturelle, Paris, France; Botanic Garden Meise, Belgium; Royal Museum for Central Africa, Tervuren, Belgium; Natural History Museum, London, United Kingdom; Royal Belgian Institute of Natural Sciences, Brussels, Belgium; Natural History Museum of Denmark, Copenhagen, Denmark. 